الرشاقة التنظيمية مدخل لتحسين القدرة المؤسسية في التعليم

\title{
الجـامعي المصري
}

د. دالة أمين مغاوري

ملخص:

يعد التعليم أحد المجالات المهمة لتقدم الأمم ورقيها، وأحد دعائم الأمن القومي؛ فهو المجال الذي يؤسس ويعد أبناء المجتمع لتحمل مسئولية مستثبل أوطانهم، فمن المهم أن تواكب النظم التعليمية التطورات الجارية، وأن تواجه التحديات المحلية والعالمية، وأن تتعامل مع التغيير برشاقة؛ حتى تتمكن من فن السير في ركب النظم التعليمية المتقدمة، خاصة أن التعليم الجامعي يهتم بإعداد الكوادر المُوََهَّة التي يتطلبها سوق العمل، بالإضافة إلى دورها في تقديم أبحاث علمية قد تفيد البشرية، بالإضافة إلى دورها في خدمة المجتمع وتتمية البيئة المحيطة بها.

$$
\text { وتهدف الدراسة الحالية إلى ما تحقيق يلي: }
$$

1- التعرف على مفهوم الرشاقة التنظيمية، وتحديد أهم المصطلحات المرتبطة

2- تحديد عناصر الرشاقة التظيمية التي تتميز بها المؤسسات الرشيقة.

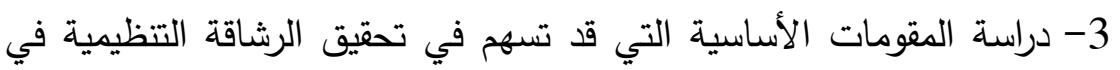
المؤسسات التعليمية. 4- التعرف على مفهوم القدرة المؤسسية في التعليم الجامعي المصري، وتحديد أهم معاييرها. 5- وضع توصيات وآليات إجرائية مقترحة لتحسين القدرة المؤسسية في التعليم الجامعي المصري، على ضوء مدخل الرشاقة التنظيمية.

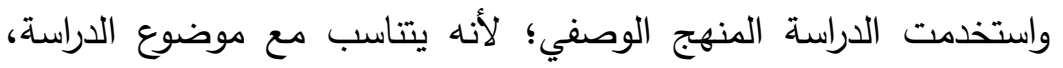

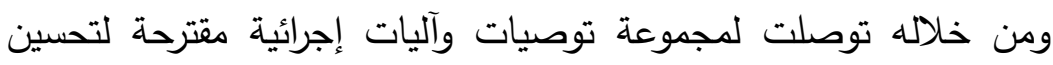
القدرة المؤسسية بالتعليم الجامعي المصري على ضوه مدخل الرشاقة التنظيمية . 


\section{Organizational Agility: An Approach to improving Institutional Capacity in Egyptian Higher Education}

Abstract:

\section{Dr. Hala Ameen Maghawri}

Education is one of the most important factors in the development of any country and one of the pillars of its national security. It also prepares young people to take the responsibility for improving the future of their countries. Therefore, in order to perform their functions effectively, it is necessary that higher educational systems cope with the pace of the accelerating change, face the international and local challenges, and deal with change with agility.

Since, higher education institutions is responsible for preparing qualified cadres that meet the needs of the labor market, providing scientific research that is used to the benefit of humanity and serving their communities, the current study aims to suggest certain recommendations and procedural mechanisms to improve the institutional capacity in Egyptian higher education in the light of the organizational agility approach. This main goal of the study is achieved through the following objectives:

- Exploring the concept of organizational agility and the terms that are closely related to it.

- Identifying the characteristics of agile organizations.

- Exploring the main factors that contribute to achieving organizational agility in educational institutions.

- Exploring the concept of institutional capacity and identifying its standards.

- Presenting the suggested recommendations and procedural mechanisms to improve the institutional capacity in Egyptian higher education in the light of the organizational agility approach.

The study used the descriptive method as it is appropriate for achieving its aim and managed, through it, to develop the suggested recommendations and procedural mechanisms to improve the institutional capacity in Egyptian higher education in the light of the organizational agility approach. 


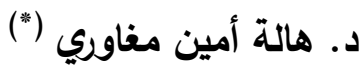

\section{مقدمة}

يشهد العالم العديد من التحديات، أبرزها ارتفاع وتيرة التغيير بشكل متسارع

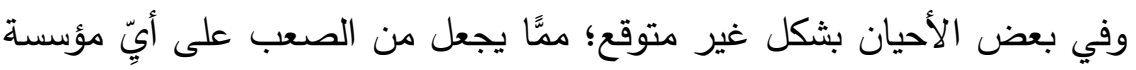

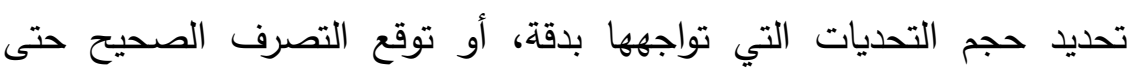

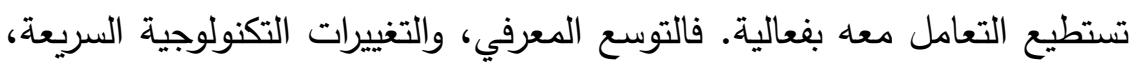
وغيرها من التطورات الحديثة والتحديات أدت إلى التغير في احتياجات العملاء ومتطلباتهم، وزيادة حدة التتافسية، واضطراب سوق العمل وعدم استقرار؛ ممّا يجعل استخدام الممارسات وأساليب العمل المعتادة لإدارة التغيير لا تكفي لمساعدة المؤسسات في مواكبة تلك التغييرات؛ مما أصبح من الضروري البحث عن أساليب عمل تمكنها من الاستجابة السريعة لمواكبة هذا التغيير، واستغلال مواردها، واستخدامها في التوقيت الصحيح. ولكي تستطيع أي مؤسسة التنافس في بيئة عمل سريعة التغيير ؛ عليها أن تكون قادرة على استشعار التغيير القادم، والاستعداد بل والاستجابة لله بسرعة ومرونة، وقراءة التغييرات الموجودة في البيئة المحيطة بها، والتتبؤ بما هو قادم - بقدر المستطاع - بل أن تكون قادرة على استغلال الفرص وتحسين أدائها، ومن ثم ظهر مفهوم الرشاقة Su, Guangya, P.371) Agility). فالرشاقة Agility تعني: مواجهة المؤسسة واستجابتها لتحديات سوق العمل، والاستفادة من التغييرات السريعة لصالح المؤسسة، وذلك بتحقيق الجودة Erande, Ameya S. and ) العالية والأداء المتميز والخدمات الجيدة Verma, Alok K., 2008, P.1 للتغييرات التي تحدث في البيئة التنافسية، والتي تعتمد على السرعة والمرونة

مجلة الإدارة التربوية مدسم أصول التربية، كلية البنات ـ جامعة عين شمس.


Hosseini, Seyyed Abdolrasoul and Others, 2013, ) والابتكار

والمؤسسات الرشيقة Agile Organizations تهنم لأبعد من مجرد

التكيف مع التغيير؛ بل إلى اعتبار التغيير فرصة لكسب ميزة تنافسية جديدة، وذلك من خلال استغلا الفرص المتاحة في بيئتها الديناميكية، وتحويل أي تهديدات إلى فرص متميزة، ومن ثََّّ الوصول إلى ميزة تنافسية تتفرد بها عن غيرها من المؤسسات الأخرى (بbesi, Saeed and Mohammadi,) (Mahdi and Shafieepur, Davood , 2013 , P.18). ويعد مدخل الرشاقة التظظيمية Organizational Agility أحد المداخل الإدارية الحديثة التي ظهرت في بداية التسعينيات من القرن العشرين في الولايات

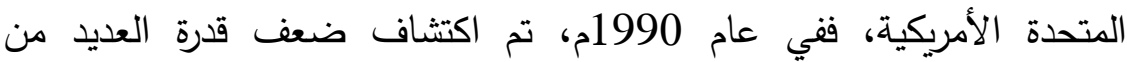
المؤسسات في المجال الصناعي الأمريكي على المنافسة أمام مثيلاتها في أسواق العمل الدولية، ومن ثََّّ قرر الكونجرس الأمريكي ـ في ذلك الوقت ــ اتخاذ

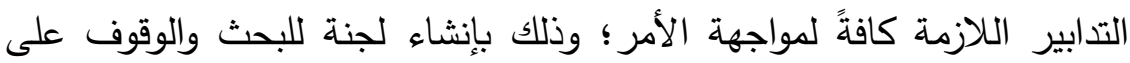
الأسباب، والذي انتهت بإصدار تقرير ليهاي Lehigh Report نسبة إلى مكان إصدار هذا التقرير من جامعة ليهاي في ولاية بنسلفانيا الأمريكية، والتي تبين ازدياد معدل التغييرات في بيئة العمل بنسبة أعلى من المعدلات المتطلبة للتتافس، ودعت لضرورة تبني: إستراتيجيات، ونظم، وأساليب عمل جديدة؛ تمكنهم من المنافسة، وذكر مفهوم الرشاقة Agility ضمن هذا التقرير، ثم تطور هذا المفهوم بعد ذلك على ضوء تزايد الحاجة لتلبية احتياجات العملاء المتغيرة وغير المتوقعة بالسرعة اللازمة لذلك ( Yeganegi, Kamran and Saber Zahiri Mohammad, 3-6 July 2012, P.2537 - Wendler, Roy, .(2013, P.1166 وباعتبار التعليم أحد المجالات المهمة لتقدم الأمم ورقيها، وأحد دعائم الأمن القومي؛ فهو المجال الذي يؤسس ويعد أبناء المجتمع لتحمل مسئولية مستقبل أوطانهم، فمن المهم أن تواكب النظم التعليمية التطورات الجارية، وأن تواجه التحديات المحلية والعالمية، وأن تتعامل مع التغيير برشاقة؛ حتى تتمكن 
من السير في ركب النظم التعليمية المتقدمة، خاصة أن التعليم الجامعي يهتم بإعداد الكوادر المُؤَهَّةَة التي يتطلبها سوق العمل، بالإضافة إلى دورها في تقديم

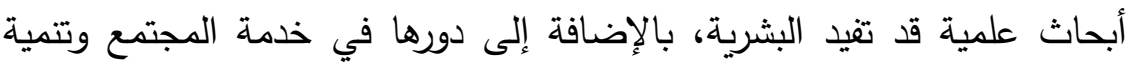

البيئة المحيطة بها.

مشكلة الدراسة وأسئلتها:

لقد أكد تقرير البنك الدولي المعد بالتعاون مع منظمة التعاون والتتمية في OECD: Organization for Economic Co-) الميدان الاقتصادي ليعيري (Operation and Development المصري للمزيد من التطوير، حيث إنه: لاتزال المركزية البالغة في حوكمة التعليم العالي المصري تشكل عقبة أمام الكفاءة المؤسسية، وبالتالي أمام القدرة التنافسية للبلد، وسوف يتعذر الإبقاء على التطورات الإيجابية، مثل: ثقافة الجودة التي تحققت بفضل مشروع إنهاه تطوير التعليم الجامعي، ونظام الاعتماد الجديد، إذا لم تحدث تغييرات جوهرية في الحوكمة وسياسات التمويل (البنك الدولي ومنظمة التعاون والتتمية في الميدان الاقتصادي، 2010م، ص ص صدية 113-114). صعوبة إخضاع رئيس المؤسسة الجامعية للمساءلة على الأداء الإجمالي لمؤسسته، وذلك لأنه لا يتمتع بالسلطة الكافية التي تئهله لاتخاذ القرارات التهات التهاه

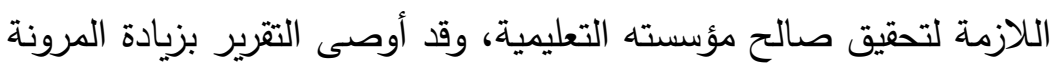
المؤسسية والقدرة على الإدارة الذاتية لتطوير التعليم العالي في مصر (البنك

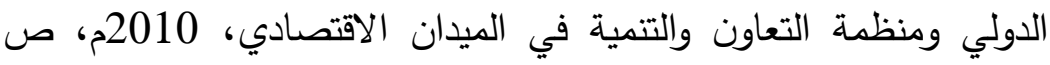
.(115

لذلك كان من الضروري الاهتمام بتطوير وتحسين القدرة المؤسسية في التعليم الجامعي المصري، والتي تهتم الهيئة القومية لضمان جودة التعليم والاعتماد بالرفع من كفاءته، وتحقيق الجودة فيه من خلال استيفاء معايير القدرة المؤسسية والفاعلية التعليمية، إلا أنه ثمة بعض أوجه القئه القصور منها: 
نسبة الكليات المتقدمة للاعتماد تمثل 11\% من إجمالي مؤسسات التعليم العالي في مصر (الهيئة القومية لضمان جودة التعليم والاعتماد، أكتوبر 2013م، ص 15)، وهي نسبة ضئيلة جدًا؛ حيث تقدمت (95) كليةً في

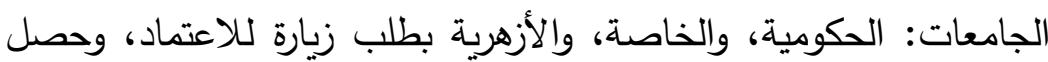

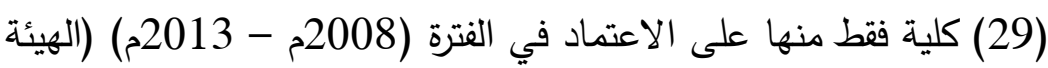

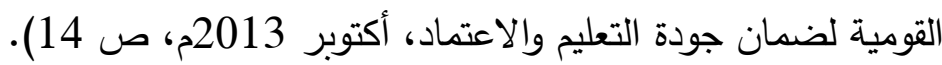
إن بعض المؤسسات الجامعية تهتم باستيفاء معايير الفاعلية التعليمية أكثر

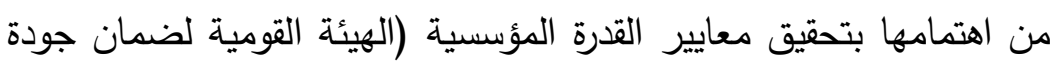

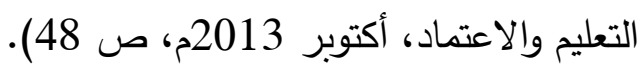
من أهم جوانب القصور في تحقيق معيار (التخطيط الإستراتيجي) في الجامعات المصرية: "ضعف حرص المؤسسات التعليمية على إجراء تقييم واقعي لوضعها التنافسي على المستويين المحلي والإقليمي، وعدم اكتمال بعض خطط التتفيذ بخصوص الإطار الزمنى، وتحديد مسئوليات التتفيذ"

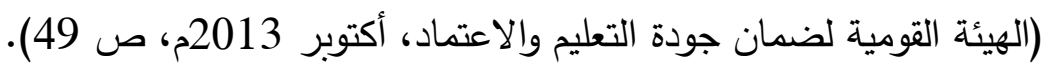
وفيما يتعلق بتحقيق معيار (القيادة والحوكمة) في الجامعات المصرية: "ضعف وجود معايير لاختيار القيادات الواقع اختيارها في نطاق السلطة التقديرية لعميد الكلية، وضعف تتمية الموارد الذاتية في مؤسسات التعليم الحكومية" (الهيئة القومية لضمان جودة التعليم والاعتماد، أكتوبر 2013م، لهونيات ص 49). (19) "محدودية دور وحدة ضمان الجودة في تطوير ومتابعة تنفيذ خطط دعم القدرة المؤسسية" (الهيئة القومية لضمان جودة التعليم والاعتماد، أكتوبر 2013م، ص 50 50. (50). وعلى ضوء ما سبق، تطرح الدراسة الأسئلة التالية:

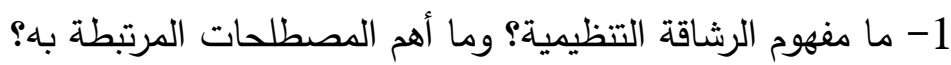

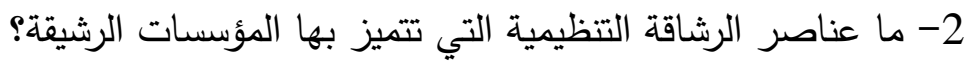


3- ما المقومات الأساسية التي قد تسهم في تحقيق الرشاقة التنظيمية في

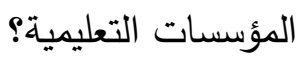

4- ما مفهوم القدرة المؤسسية في التعليم الجامعي المصري؟ وما أهم معاييرها؟ 5- ما التوصيات والآليات الإجرائية المقترحة لتحسين القدرة المؤسسية في مائي

التعليم الجامعي المصري على ضوه مدخل الرشاقة التنظيمية؟

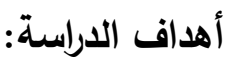

تهدف الدراسة الحالية إلى ما تحقيق يلي: 6- التعرف على مفهوم الرشاقة التظيمية، وتحديد أهم المصطلحات المرتبطة

7- تحديد عناصر الرشاقة التظيمية التي تتميز بها المؤسسات الرشيقة.

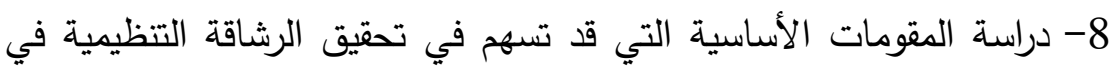

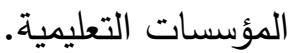
9- التعرف على مفهوم القدرة المؤسسية في التعليم الجامعي المصري، وتحديد أهم معاييرها.

10- وضع توصيات وآليات إجرائية مقترحة لتحسين القدرة المؤسسية في التعليم الجامعي المصري، على ضوء مدخل الرشاقة التنظيمية. أهمية الدراسة: تتضح أهمية الدراسة من خلال ما يلي:

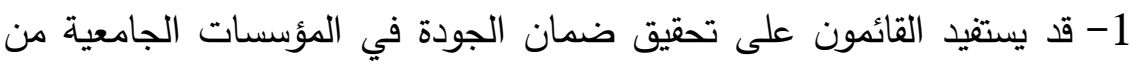
هذه الدراسة؛ من خلال التعرف على كيفية تحسين القدرة المؤسية بفكر إداري جديد (الرشاقة التنظيمية) لتحقيق الجودة بها. 2- قد تسهم الدراسة الحالية بفتح المجال أمام المزيد من الدراسات عن الرشاقة لتهات التنظيمية، وكيفية توظيفها لتطوير التعليم في مصر ؛ باعتباره أحد المداخل الإدارية الحديثة التي لم تجد الباحثة ـ على حد علمها ـ حتى الآن دراسات سابقة عربية تتاولت هذا الموضوع، ومن ثم تعد الدراسة الحالية من أوائل الدراسات العربية ـ على حد علم الباحثة ـ التي تتاولت الرشاقة التنظيمية. 


\section{حدود الدراسة}

اقتصرت الدراسة الحالية على تتاول ثلاثة معايير فقط من معايير القدرة

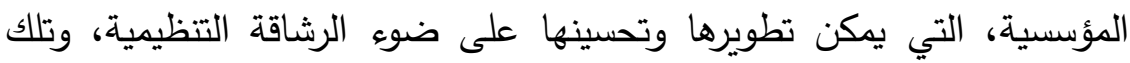
المعايير هي: (التخطيط الإستراتيجي، والهيكل التنظيمي، والقيادة والحوكمة)، والتي قد تسهم بشكل ما في تحسين القدرة المؤسسية في التعليم الجامعي

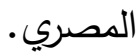

\section{منهج الاراسة:}

استخدمت الدراسة المنهج الوصفي؛ لأنه يتناسب مع موضوع الدراسة،

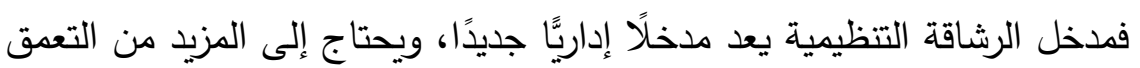
في مفهومه، وتحليل عناصره، وفهم أهم دقوماته، وتفسيرها، والتعرف على كيفية

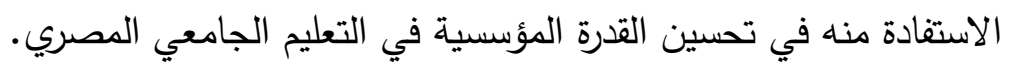
مصطلحات الاراسة:

\section{تتحدد مصطلحات الدراسة فيما يلي:}

\section{1- الرشاقة التظيمية Organizational Agility:}

\section{لقد اهتمت العديد من الأدبيات المختلفة بدراسة هذا المفهوم، وكيفية}

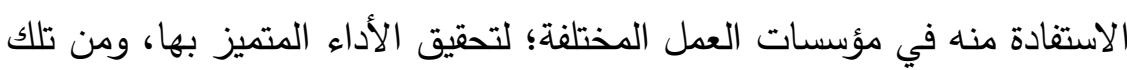
التعريفات أنه يعني: خفة الحركة داخل المؤسسة، والاستجابة السريعة للتغيرات المتواجدة في بيئة العمل المحيطة بها؛ من أجل تحقيق أهدافها، وذلك من خلال

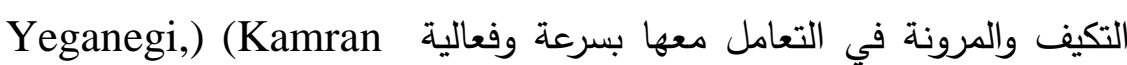
.and Saber Zahiri, Mohammad, 2012, P.2538

أما عن مفهومه في الأدبيات التربوية، فلم تجد الباحثة ـ على حد علمها ـ حتى الآن دراسات تتاولت هذا المفهوم في المجال التربوي؛ نظرًا لحداثة هذا لهاب المصطلح نسبيًا، وقد حددت الدراسة الحالية المفهوم الإجرائي لمصطلح الرشاقة التنظيمية، والذي يعني جميع الممارسات والأساليب التي تتيح للمؤسسة الجامعية مواكبة التغيير، وسرعة التعامل معه بفعالية وابتكار، بل والاستفادة منه في لهي تحسين قدرتها المؤسية، وبما يتماشى مع تحديات البيئة التنافسية المحيطة بها. 


\section{2- القدرة المؤسسية Institutional Capacity:}

وتتبنى الدراسة الحالية المفهوم الذي حددته الهيئة القومية لضمان جودة

التعليم والاعتماد لمصطلح (القدرة المؤسسية) في التعليم الجامعي المصري، والذي عرفته بأنه: " قدرة المؤسسة على الأداء بكفاءة من خلال الموارد البشرية والمادية المتاحة؛ وذلك لتحقيق رسالتها، وغاياتها، وأهدافها الإستراتيجية المعلنة، مع وجود هيكل تتظيمي ملائم ينطوي على علاقات واضحة للسلطة، وتحديد دقيق للمسئوليات والاختصاصات، وفي ظل قيادة أكاديمية وإدارية موجهة بالتخطيط الإستراتيجي، وتتصف بالمصداقية والشفافية، إضافة إلى قدرة المؤسسة على التفاعل مع المجتمع، وعلى إنشاء نظم داخلية لإدارة الجودة، وإجراء التقويم المستمر لأدائها الكلي" (الهيئة القومية لضمان جودة التعليم والاعتماد، أغسطس

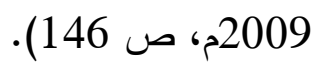
الاراسات السابقة:

ومن الدراسات السابقة المرتبطة بموضوع الدراسة (عربيَّا وأجنبيَّا)، والتي تم تصنيفها إلى محورين، محور (الرشاقة التظيمية)، ومحور (القدرة المؤسسية)، والتي تم ترتيبها في كل محور على حدة ترتيبًا زمنيًّا، من الأقدم إلى الأحدث وفق ما يلي: المحور الأول: الدراسات السابقة التي تناولت (الرشاقة التظيمية): ومن الدراسات السابقة التي تتاولت (الرشاقة التظيمية)، ما يلي: 1 دراسة Kamran and Mohammad، (2012م)، بعنوان: "تأثير تكنولوجيا المعلومات على الرشاقة التنظيمية"، وقد هدفت الدراسة إلى بلى التعرف على تأثير تكنولوجيا المعلومات على الرشاقة التنظيمية في مؤسسات العمل، وقد استخدمت الدراسة المنهج الوصفي. ومن أهم النتائج التي مؤي توصلت إليها، ما يلي: أ- تيسير وتسريع الاتصالات الداخلية بين العاملين داخل المؤسسة من جهة، وبينهم وبين العملاء من جهة أخرى. 
ب-تدعيم الرشاقة التنظيمية من حيث: توافر المعلومات المطلوبة عن بيئة العمل المحيطة بها بالسرعة والدقة المطلوبة، واستخدام برامج إلكترونية تساعد على تحقيق المرونة في إتمام العمل. Software ج- تساهم في تدفق البيانات وسرعة معالجتها؛ للوصول إلى المعلومات المطلوبة؛ مما يساهم في سرعة صنع واتخاذ القرار داخل المؤسسة. د- تزيد من الانسجام والتوافق بين وحدات وأقسام المؤسسة، والاستغلال الأمثل للموارد البشرية؛ ممّا يساهم في تلمية الرشاقدة التنظيمية داخل Yeganegi, Kamran and Saber Zahiri,) المؤسسة. (Mohammad, 3-6 July 2012, PP.2537-2544

2-2 دراسة Seyyed and others، (2013م)، بعنوان: "دور القيادة الخدمية في تحقيق الرشاقة التظيمية ــ دراسة حالة على مؤسسة فارس للأمن الاجتماعي"، وقد هدفت الدراسة إلى التعرف على دور القيادة الخدمية في تحقيق الرشاقة التنظيمية، وقد استخدمت (Servant Leadership) الدراسة المنهج الوصفي، وقد تم تطبيق استبانة على عينة قوامها 102 فردٍ من العاملين في مؤسسة فارس للأمن الاجتماعي، ومن أهم النتائج التي لتئي توصلت إليها أن عناصر القيادة الخدمية لهم دور مؤثر في تحقيق الرشاقة التظيمية داخل المؤسسة. Hosseini, Seyyed Abdolrasoul and) (Others, 2013, PP. 2935-2943

3- دراسة Abe and others، عام 2015م، بعنوان: "الرشاقة التنظيمية"،

وقد هدفت الدراسة إلى التعرف على مفهوم الرشاقة التنظيمية من خلال تحليل بعض الأدبيات ذات الصلة بالموضوع، ووضع إطار مفاهيمي له، وقد استخدمت الدراسة المنهج الوصفي. ومن أهم النتائج التي توصلت إليها الدراسة أنها وضعت إطارًا للرشاقة التنظيمية، يعتمد على عشر ركائز هي:

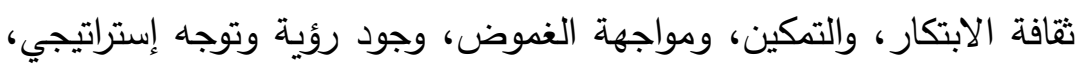

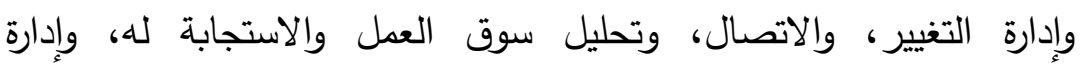


العمليات، والمرونة في الهيكل التنظيمي، والاهتمام بالتعلم التنظيمي)، وأنه

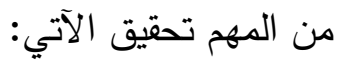
نشر ثقافة الرشاقة التنظيمية؛ لما لها من دور أساسي في جعل المؤسسة أكثر استجابة للتغيرات في بيئتها الخارجية. أن تلك الركائز تختلف من مؤسسة لأخرى، طبقا لطبيعة مجالها ووفقا لاحتياجاتها الأساسية وكيفية توظيفها. Harraf, Abe and Others,) March/April (2015, PP.675-686 4- دراسة أنس وأسعد (Anas and As'ad)، عام 2015م، بعنوان:

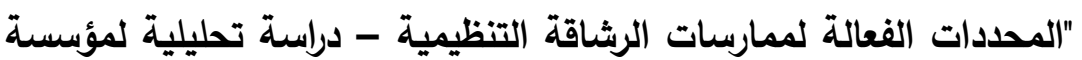
تكنولوجيا المعلومات في الأردن"، وقد هدفت الدراسة إلى التعرف على

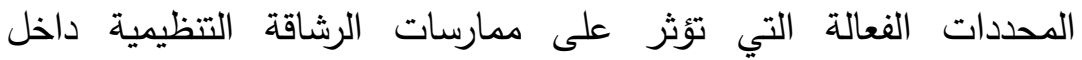
المؤسسة، وقد استخدمت الدراسة المنهج الوصفي، وقد تم تطبيق استبيان على عينة مكونة من 250 موظفًا من 12 شركة كبرى في مجال الاتصالات

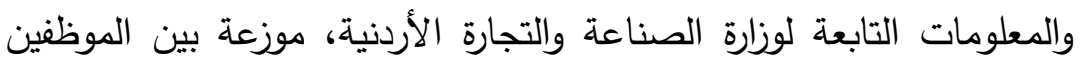
في مستوى الإدارة العليا، ومستوى الإدارة الوسطى بتلك الشركات، ومن أهم النتائج التي تم التوصل إليها أن محددات الرشاقة التنظيمية (إدارة الموارد

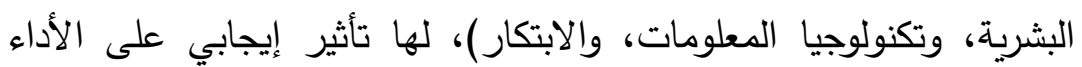
التظيمي للمؤسسة والمتمثل في (الأداء المالي، والأداء التشغيلي) لها. Alhadid, Anas Y. and Abu-Rumman, As'ad, March) 2015, (PP.34-39

المحور الثاني ـ الدراسات السابقة التي تناولت (القدرة المؤسسية): ومن الدراسات السابقة التي تتاولت (القدرة المؤسسية)، ما يلي: 1- دراسة أحمد مرعى هاشم، عام 2009م، بعنوان: "متطلبات بناء القدرات

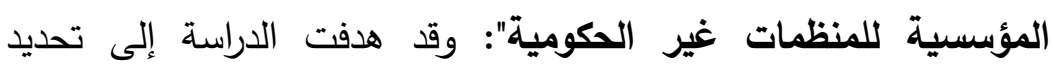
المتطلبات اللازمة لبناء القدرات المؤسسية للمنظمات غير الحكومية 
(الجمعيات الأهلية) بالفيوم. ومن أهم النتائج التي توصلت إليها الدراسة، ما يلي: أ- بالرغم من اهتمام الجهات الأهلية بتقديم البرامج التدريبية التي تهتم بيناء

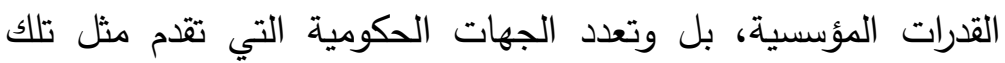
البرامج (وزارة التضامن الاجتماعي، والمجلس القومي للمرأة، والهيئات

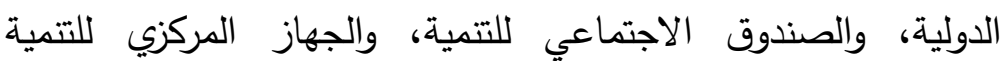

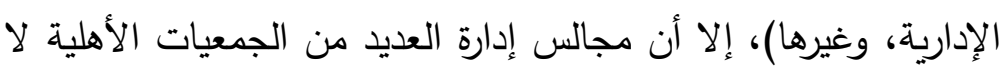

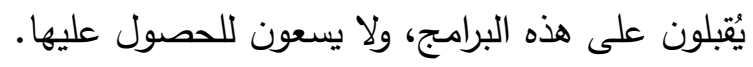

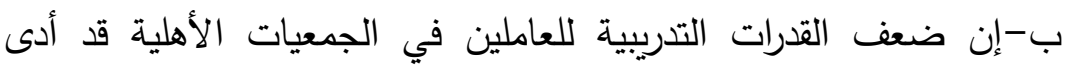
بشكل أو بآخر إلى ضعف القدرات المؤسسية لتلك الجمعيات. (أحمد

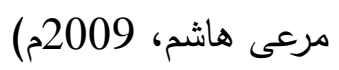

2- دراسة كريمة عيد كامل، عام 2009م، بعنوان: "برنامج مقترح لاور

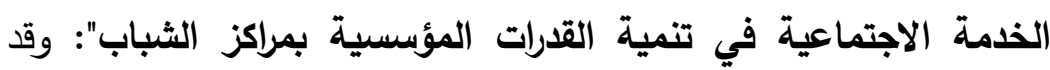
هدفت الدراسة إلى تحديد الواقع الفعلي للقدرات المؤسسية في مراكز لهراته الشباب، وهي: القدرات التمويلية، والقدرات التدريبية، وقدرات الاتصال

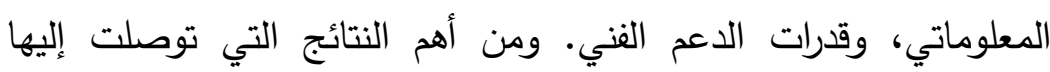
الدراسة إعداد برنامج مقترح لدور الخدمة الاجتماعية في تتمية القدرات

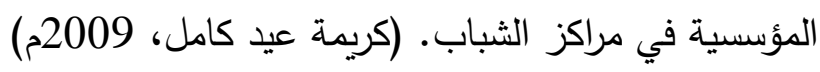
3- دراسة محمد محروس شحاتة، عام 2012م، بعنوان: "قياس القدرة

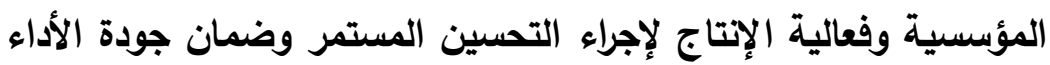
في المؤسسات الصحفية"، وقد هدفت الدراسة إلى التعرف على الإنى مدى التى

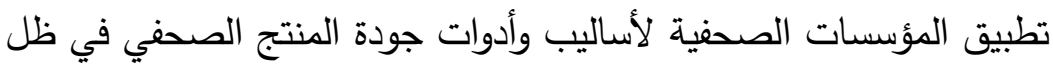

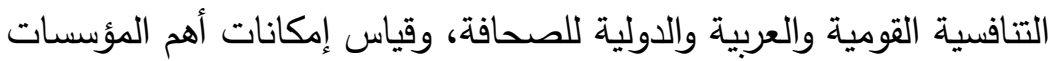

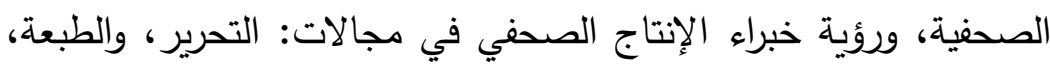
والتوزيع، والإعلانات بشأن المعايير التي يجب التئه أن تطبقها المؤسسات الصحفية، وتلتزم بها للبقاء في مجال التتافسية الإعلامية. ومن أهم النتائج

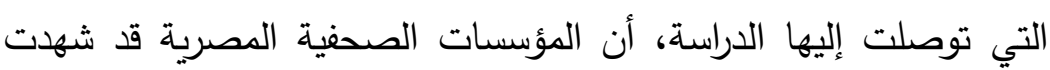

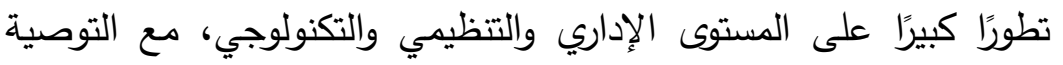
العدد العاشر - سبتمبر 2016 مجلة الإدارة التربوية 
بضرورة تطوير النماذج والإستراتيجيات الإدارية التقليدية في المؤسسات

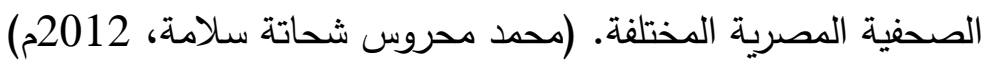
4- دراسة هدير محمد عبد الله، عام 2015م، بعنوان: "التخطيط

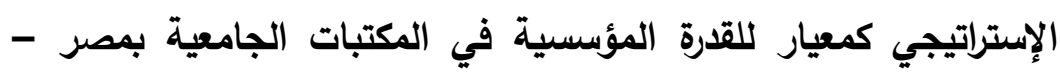
دراسة ميدانية"، وقد هدفت الدراسة إلى تحليل الخطط الإستراتيجية

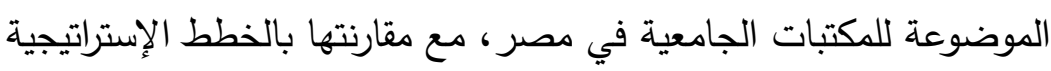

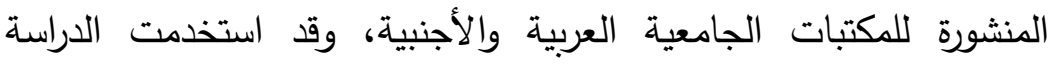
المنهج الوصفي، وقد تم تطبيق استبانة موجهة لمديري المكتبات الجامعية. ومن أهم النتائج التي تم التوصل إليها:

أ- قيام أكثر من نصف المكتبات الجامعية في مصر بوضع خطط التطاء إستراتيجية للمكتبة، سواء كانت خطة مستقلة للمكتبة، أو الاكتفاء بالاشتراك في خطة الجامعة الإستراتيجية.

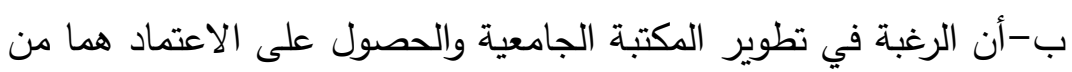

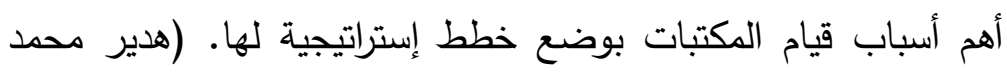

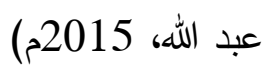

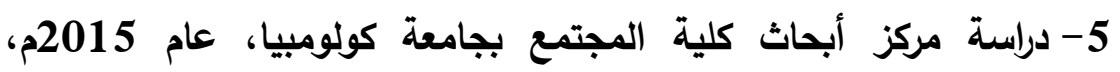

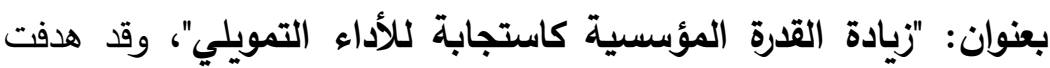

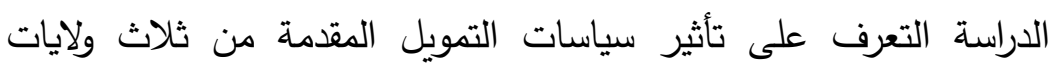

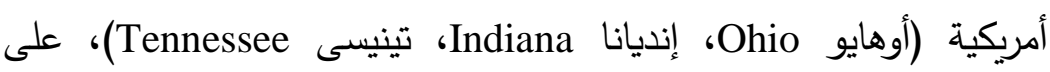
الأداء المؤسسي لكليات المجتمع بها، وتأثير ذلك على الجهود المبذولة

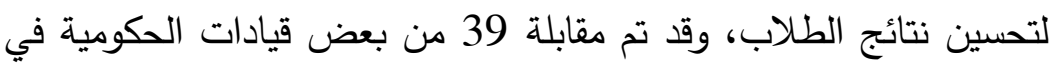
تلك الولايات، و222 إداري وعضو هيئة تدريس في 18 كلية من كليات

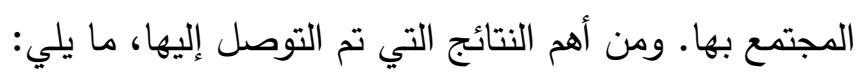
أ- افتقار تلك الكليات إلى القدرات المؤسسية التي تمكنهم من تحسين نتائج الطلاب، خاصة أن تكلفة الأداء المؤسسي أعلى بكثير من التمويل الحكومي المقدم لهم. 
ب- التوصية بتقديم التمويل اللازم لزيادة القدرات المؤسسية بها، والمتمثلة

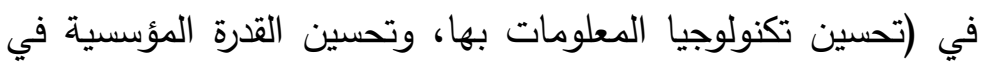
مجال البحث العلمي، ومساعدة المؤسسات في التغيير الإيجابي والتطوير، وتقديم برامج تعليمية جديدة). Community College) (Research Centers, January, 2015 أوجه التثابه والاختلاف بين الدراسات السابقة والدراسة الحالية يتضح مما سبق، وجود العديد من الدراسات السابقة الأجنبية التي تتاولت موضوع الرشاقة التظيمية في مجالات عمل مختلفة، وقد استفادت منهم الدراسة

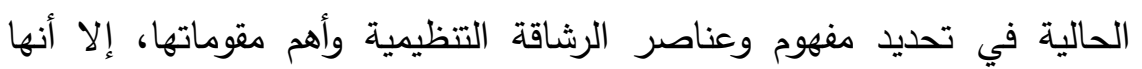
تختلف عنهم في محاولة تحقيقه في مجال التعليم الجامعي، وذلك من خلال

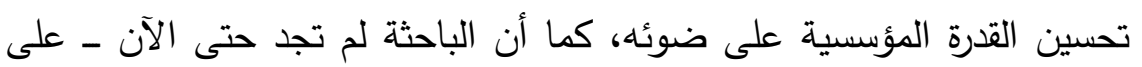
حد علمها ـ دراسات عربية تناولت هذا الموضوع؛ نظرًا لحداثة المصطلح.

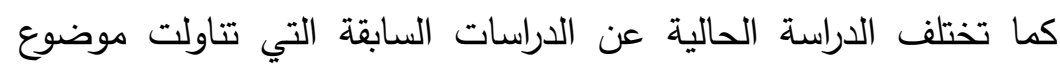
القدرة المؤسسية، في أن الدراسة الحالية تبنت مفهوم القدرة المؤسسية الذي حددته

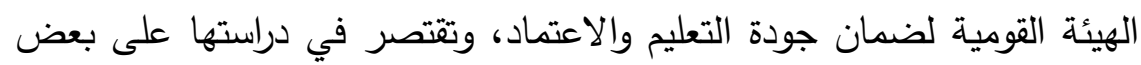
المعايير التي يمكن تحسينها بفكر الرشاقة التنظيمية وهي: (التخطيط الإستراتيجي، والهيكل التظظيمي، والقيادة والحوكمة)، كما اختلفت الدراسات السابقة العربية والأجنبية فيما بينها في تتاول موضوع القدرة المؤسسية، وذلك لأن عناصره تختلف من مؤسسة إلى أخرى تبعًا لطبيعة مجال العمل محل الدراسة. خطوات الدراسة تسير الدراسة وفقًا للدحاور التالية: المحور الأول: الرشاقة التظيمية في المؤسسات التعليمية، وذلك من خلا توضيح ما يلي: أولًا: مفهوم الرشاقة التتظيمية، وأهم المفاهيم المرتبطة بها. ثانيًا: عناصر الرشاقة التظظيمية التي تتميز بها المؤسسات الرشيقة. ثالثًا : المقومات الأساسية لتحقيق الرشاقة التنظيمية بالمؤسسات التعليمية. 
المحور الثاني: القدرة المؤسسية في التعليم الجامعي المصري، وذلك من خلال توضيح ما يلي: أولًا: مفهوم القدرة المؤسسية في التعليم الجامعي المصري. ثانيًا: معايير القدرة المؤسسية في التعليم الجامعي المصري. المحور الثالث: توصيات وآليات إجرائية مقترحة لتحسين القدرة المؤسسية في التعليم الجامعي المصري على ضوء مدخل الرشاقة التنظيمية. وتتتاول الدراسة تلك النقاط بشيء من التقصيل، كما يلي: المحور الأول ـ الرشاقة التنظيمية في المؤسسات التعليمية: وتوضحه الدراسة كما يلي: أولاً مفهوم الرشاقة التظيمية، وأهم المفاهيم المرتبطة به: وتعرضسه الدراسة كما يلي:

1- مفهوم الرشاقة التنظيمية Organizational Agility: يعود أصل كلمة رشاقة في اللغة العربية إلى الفعل " رَشُقَ بالضم، رشاقة.

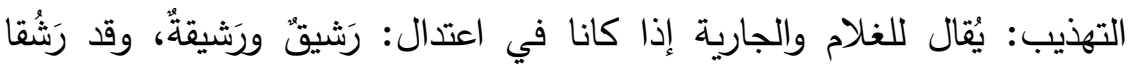

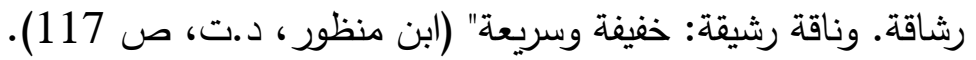

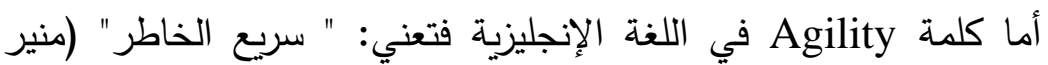
بعلبكي، 1995م، ص 34)، والصفة Agile تعنى " الرشيق، خفيف الحركة أو

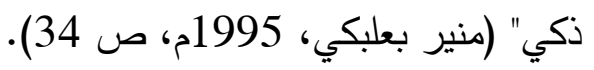
ومن التعريفات التي تتاولت مفهوم الرشاقة Agility في مؤسسات العمل، تعريف (Ameya and Alok) بأنها القدرة على الاستجابة السريعة للتغييرات غير المتوقعة، وتحقيق الربحية للمؤسسة. كما أنها تعني الاستجابة الشاملة

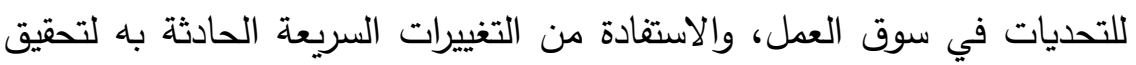

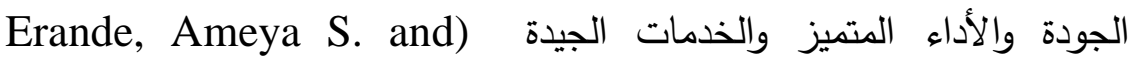
(Verma, Alok K., 2008, P.1 كما عرفها (Guangya) بأنها: قدرة المؤسسة على استثعار التغييرات المتوقعة وغير المتوقعة في بيئة العمل، والاستجابة لها بسرعة أكبر وبفعالية، بانها: 
واغتنام الفرص الممكنة الراجعة عن هذا التغيير، وذلك عن طريق الاهتمام باستثمار الكفاءات وتدعيم الاستباقية (Su, Guangya, P.371). وقد عرفها (Kamran and Mohammad) بأنها: القدرة على الاستجابة للتغييرات غير المتوقعة بسرعة وتحقيق الربحية ( Yeganegi, Kamran and .(Saber Zahiri, Mohammad, 3-6 July 2012, P.2538 أما (Ray) فقد عرفها بالتكامل الفعال بين قدرة المؤسسة على الاستجابة وكيفية إدارتها للمعرفة من حيث السرعة والكفاية والتكيف مع أي تغييرات غير متوقعة، والاستفادة من الفرص دون الإخلال بنوعية المنتج أو العمليات المستخدمة أو زيادة التكلفة (Wendler, Roy, 2013, P.1166). ويرى (Saeed, Hahdi and Davood) أنها: القدرة على الاستجابة بسرعة واتخاذ رد فعل مناسب ومتزامن مع التغييرات الحادثة في البيئة الخارجية (Abesi, Saeed and Mohammadi, Mahdi and Shafieepur, .(Davood , 2013 , P.19

كما عرفها (Seyyed and others) بأنها: القدرة على الاستجابة والتعامل مع التغييرات في بيئة العمل الخارجية بسرعة وفي الوقت المناسب، كما أنها تهتم بالتسيق التنظيمي الوثيق مع احتياجات سوق العمل المتغيرة، من أجل اكتساب ميزة تتافسية (Hosseini, Seyyed Abdolrasoul and Others, .(2013, P.2936

وأما عن مفهوم الرشاقة التنظيمية Organizational Agility في الأدبيات المختلفة، فقد اختلفت طبقًا لنوع المؤسسة أو مجال العمل الذي يتبنى تطبيق هذا المفهوم، إلا أن معظمها يدور حول مفهوم الرشاقة Agility الذي تم توضيحه سابقًا، ومن تلك التعريفات تعريف ( ) (Jin , Deliang and Shan) للرشاقة التتظيمية بأنها: مجموعة من القدرات التتظيمية التي تسمح للمؤسسة باستشعار التغييرات في بيئة العمل المضطربة بفعالية، والاستجابة لتلك التغييرات في الوقت المناسب، من خلال المواءمة المستمرة بين القدرات والموارد بفعالية، Chen, Jin) and وتحقيق الكفاءة مع الأخذ في الاعتبار لعامل التكلفة (Wang, Deliang and Pan, Shan L. , 9July 2011, PP.2-3 العدد العاشر - سبتمبر 2016

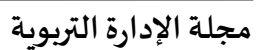


كما عرفها (Anas and As'ad) بأنها: الاستجابة السريعة للتغيير في بيئة عمل المؤسسة، والتغلب على العقبات من خلال كسب فرص ومزايا تتافسية جديدة (Alhadid, Anas Y. and Abu-Rumman, As'ad, March) .$(2015$, P.35

وقد عرفها (Roy and Tu) بأنها: إعادة تشكيل الموارد، واستخدام أفضل أساليب العمل الممكنة؛ لتحقيق التكامل الفعال بين قدرة المؤسسة على الاستجابة

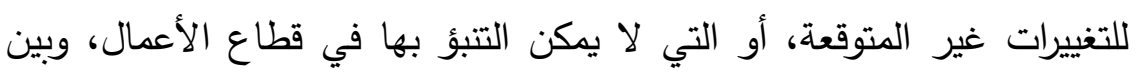

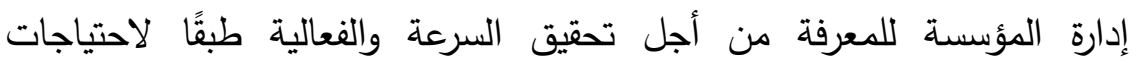

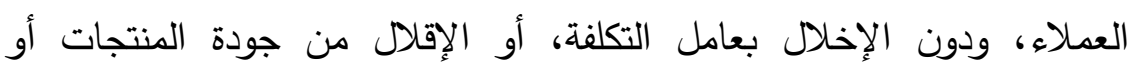

(Wendler, Roy and Dresden, Tu, 2014, P.1198). العمليات ويتضح مما سبق، أن مفهوم الرشاقة التظيمية إذا ما طبق في مجال التعليم الجامعي، فقد يسهم في الرفع من قدرة المؤسسة التعليمية على استثعار

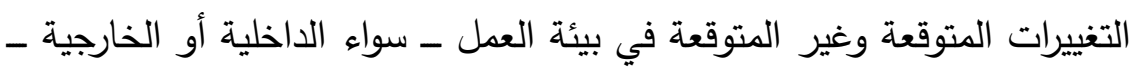
وسرعة الاستجابة لها، والتعامل معها بفعالية وابتكار، والاستفادة من تلك التغييرات باكتشاف فرص جديدة، واستثمارها وتحويلها إلى ميزة تتافسية جديدة،

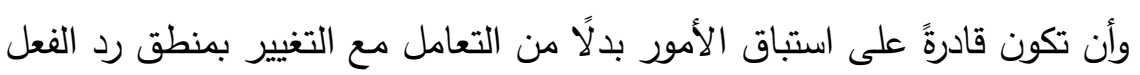
اتجاهه فقط.

كما يتضح أن المؤسسات الرشيقة Agile Organizations تختلف عن المؤسسات الجامدة Rigid Organizations في أن الأخيرة بحاجة إلى كسر طريقة التثكير التقليدية، وتشجيع الابتكار، وتعلم كيفية اكتشاف الفرص الجديدة، واستثمارها؛ لرفع كفاءتها، ففي حين اهتمام المؤسسات الرشيقة بالاستجابة

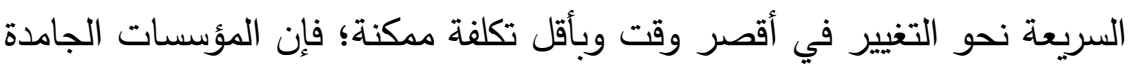
تتمسك بأداء العمل بنفس الأساليب التقليدية الروتينية، والتي قد تسبب أحيانًا في

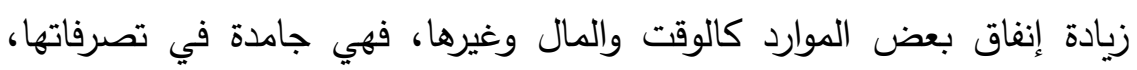
وطريقة تعاملها مع المواقف المختلفة، وتهدف فقط إلى البقاء حتى لو كان ما لـ 
Su, Guangya,) تقمه ضعيفًا، أو لا يلبي احتياجات الكثير من العملاء .(P.374

والمؤسسات الرشيقة تقتتص الفرص وسط تلك التغييرات وتغتتمها؛ لتحويلها

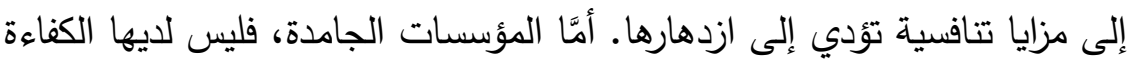
المطلوبة لاستباق الأمور أو المبادرة، والتغيير بالنسبة لها يجلب الفوضىهى، وتكتفي فقط في مواجهة هذا التغيير إلى التوسع في حجمها، وازدياد حدود

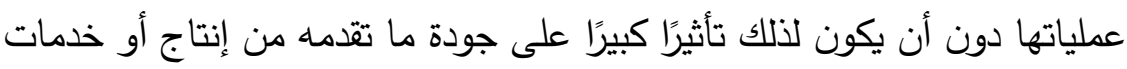
.(Su, Guangya, P.374)

\section{2- المفاهيم المرتبطة بمفهوم الرشاقة التنظيمية:}

هناك بعض المفاهيم التي قد تتداخل مع مفهوم الرشاقة التتظيمية، كمفهوم المرونة (Flexibility)، فقد اتفقت العديد من الدراسات على أن المرونة تعني قدرة المؤسسة على إنجاز عدة عمليات مختلفة في نفس الوقت، مع تقديم Yeganegi,) التيسيرات اللازمة لإتمامها وذلك لتحقيق الأهداف بفعالية Kamran and Saber Zahiri, Mohammad, 3-6 July 2012, P.2539 -- Abesi, Saeed and Mohammadi, Mahdi and Shafieepur, Davood, 2013, P.19 -- Almahamid, Soud (Mohammad, 2013,

كما تساعد المرونة في التعامل مع التغييرات المتوقعة في بيئة العمل الداخلية أو الخارجية، والتحكم بها من خلال التخطيط المسبق لها بغض النظر عن السرعة المطلوبة، بينما تستطيع الرشاقة التعامل مع التغييرات غير المتوقعة والتي تمثل أكثر تحديًا، ممَّا يتحتم سرعة الاستجابة لها بطريقة مبتكرة، واتخاذ

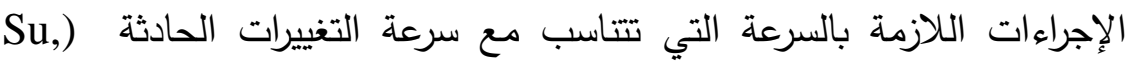
.Guangya, P.374 - Wendler, Roy, 2013, P.1166 ومن ثم يتضح أن مفهوم الرشاقة أعم وأشمل من مفهوم المرونة، بل من الممكن اعتبار المرونة عنصر من العناصر التي قد تسهم في تحقيق الرشاقة

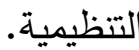

أما عن مفهوم الهزال أو العجاف (Lean)، والذي يترجم في بعض الدراسات العربية إلى كلمة رشاقة كما في دراسة (محمد موفق أحمد المكي) والتي 
بعنوان (مقدمة إلى الستة سيجما الرشيقة)، والذي ترجم فيها كلمة (Lean) إلى (الى

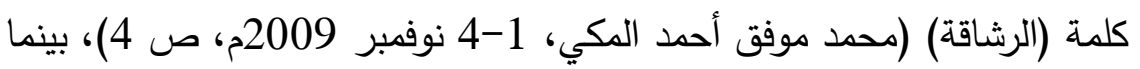
ترى الباحثة أنها ترجمة ليست في محلها، وذلك لأن ترجمتها تعنى " هزيل،

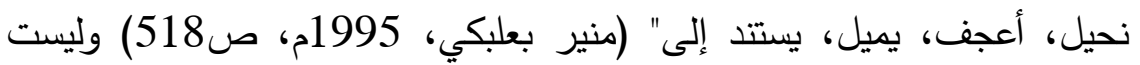

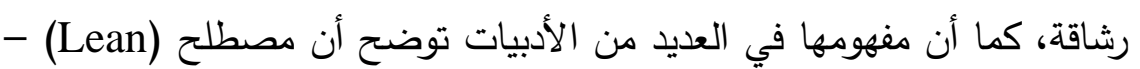
ويكتب أحيانا باللغة الإنجليزية (Leanness) للتغرقة بين الصفة (Adjective) والاسم (Noun)- فتعني القضاء على جميع أشكال الهدر، كإهمال العمليات والأنشطة التي ليس منها جدوى، والتخلص من الأشياء التي ليست لها فائدة أو قيمة، والقضاء على جميع التكاليف غير الضرورية لتحقيق أفضل النتائج بأقل Gilaninia, Shshram and Others December) تكلفة وفي أقصر وقته وئح 2011, P.47 -- Aitken, James and Christopher, Martin and Aowill, Denis - Wendler, Roy, 2013, P.1166)، وقد أكدت دراسة (محمد موفق أحمد المكي) هذا الأمر عندما أوضحت أن ( Lean) هي " فلسفة تسعى إلى حذف الهدر من كل أوجه نشاطات إنتاج شركة معينة، والعلاقات العامة، والمبيعات، والتكنولوجيا، وإدارة الموارد والمخزون" (محمد موفق أحمد المكي، 1-4 نوفمبر 2009م، ص 6)، وهو ما يؤكد وجهة نظر الباحثة في أن

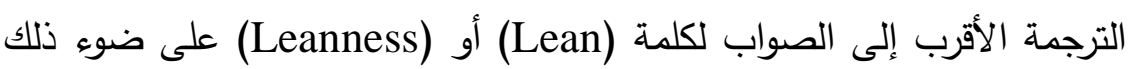
هي الهزيل أو الهزال. ومن ثم فإن الفرق واضح لغةً واصطلاحًا بين مفهوم الرشاقة (Agility)، وبين مفهوم الهزال (Leanness)، حيث إن الهزال لا يمكن استخدامه إلا مع أشياء محددة وصريحة وواضحة، في بيئة عمل مستقرة نسبيًا، ويمكن التنبؤ بالتغيير الحادث فيها بغض النظر عن السرعة المطلوبة، والذي يعتمد على تقليل حجم المؤسسة أو الأنشطة التي تتم بها، من خلال القضاء على كل كل ما ليس له له فائدة أو قيمة، أما الرشاقة فتهتم بالتفكير الذكي والتصرف التشهي السريع في التعامل مع داء

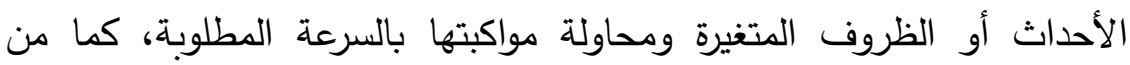
الممكن اعتبار الهزال أحد الأساليب التي قد تسهم في تحقيق الرشاقة التنظيمية 
Gilaninia, Shshram and Others,) (December بطريقة أو بأخرى .2011, P.47 - Wendler, Roy, 2013, P.1166 ثانيًا عناصر الرشاقة التظيمية التي تتميز بها المؤسسات الرثيقة: يوضح شكل (1) والذي أعدته الباحثة أهم العناصر التي تمثل السمات التي تتصف بها المؤسسات الرشيقة، وهي كما يلي:

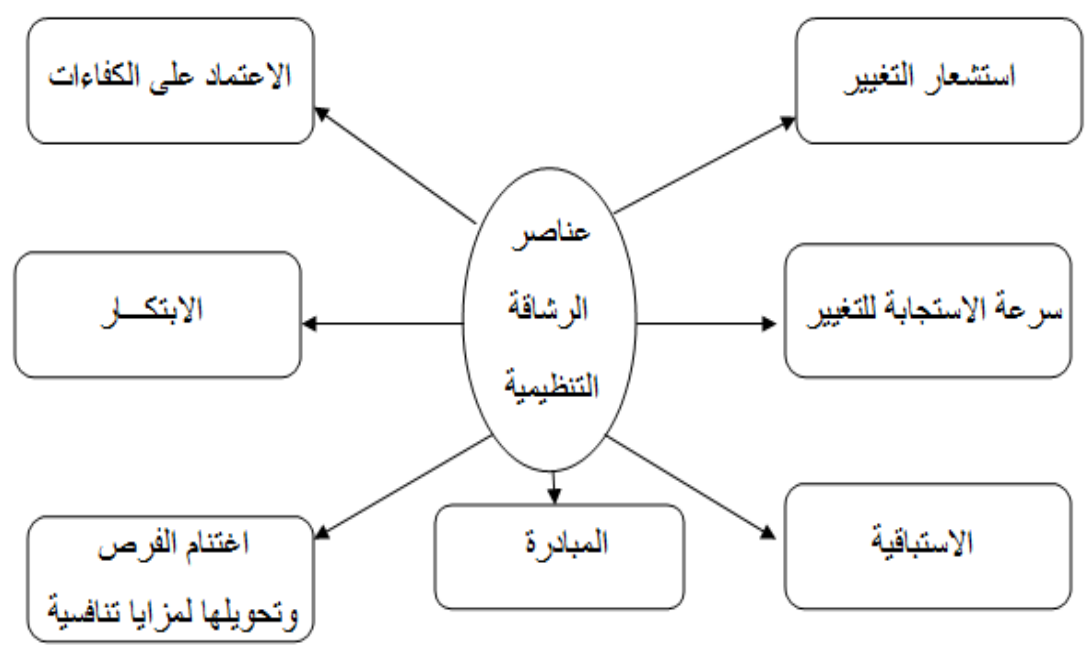

شكل (1) عناصر الرشاقة التنظيمية (")

ويتضح من الثكل السابق، أن أهم عناصر الرشاقة التظيمية، ما يلي:

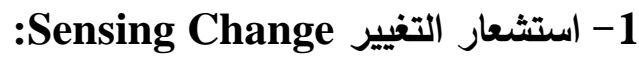

ويعني قدرة المؤسسة على تحديد عوامل التغيير الحادثة في بيئة العمل -

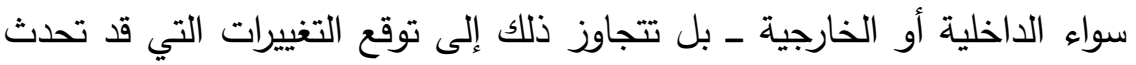
في المستقبل والاستعداد لها من خلال وضع رؤى وخطط واستراتيجيات قوية لمواجهة ذلك، وتطوير أدائها باستمرار وابتكارأساليب عمل جديدة تسهم في وفي وحني تحقيق أهداف المؤسسة بفعالية، وتجعلها قادرة على مواصلة جهودها لفترات

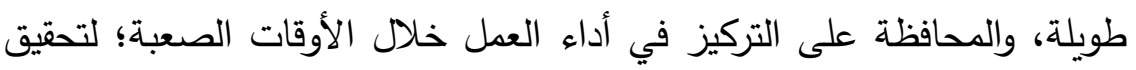
Chen, Jin and Wang, Deliang and Pan,Shan L. ,) النجاح المنشود لكودير

(9July 2011, PP.2-3 
2- سرعة الاستجابة للتغيير Rapid of Responding to Change:

وتعني قدرة المؤسسة على تشخيص التغيير، والتفاعل معه، والاستجابة الاقيقة له بنفس سرعته وفي الوقت المناسب، فمن المهم أن تواكب المؤسسة

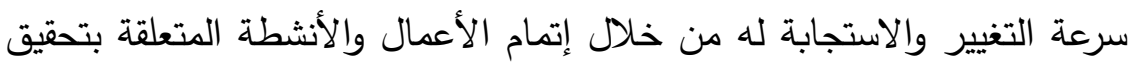

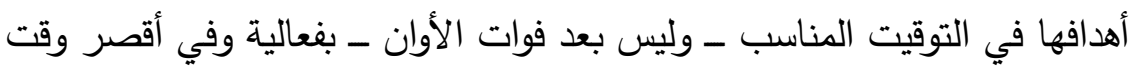
مكن July 2012, P.2539 -- Abesi, Saeed and Mohammadi, Mahdi (and Shafieepur, Davood , 2013 , P.19

\section{3- الاستباقية Proactive:}

وتعني قدرة المؤسسة على اتخاذ إجراءات تسبق بها الأحداث وتكون سبّاقة في ذلك عن مثيلاتها في سوق العمل، فلكي تحافظ المؤسسة على بقائها في عصر يتسم بالتغيير المستمر؛ فمن المهم أن تبادر بتقديم كل ما هو جديد؛ لكي تواكبه، كتقديم خدمات بطرق جديدة أو منتجات مبتكرة، أو أنشطة وإجراءات

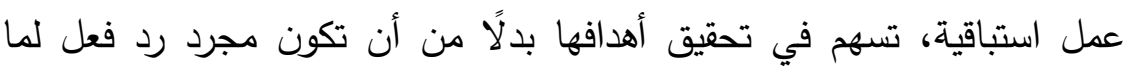

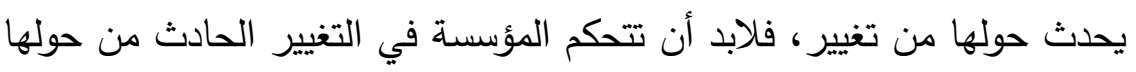

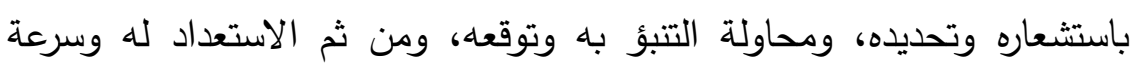

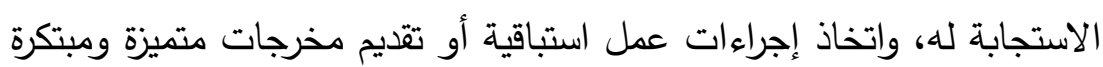
(Mehrabi, Soheila and Siyadat, Sayyed Ali and Allameh, Sayeed Mohsen, May2013, P.317 - Harraf, Abe and Others, (March/April 2015, P.675

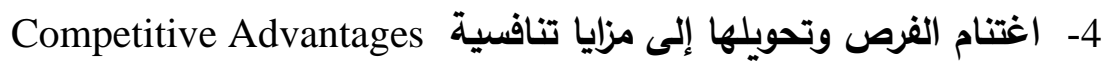
ويعني قدرة المؤسسة على مواجهة التغييرات والاستفادة منها، من خلال الكشف عن فرص حقيقية للأداء التتافسي في بيئة العمل، أو تحويل التهديدات إلى فرص ونقاط قوة لها، ومن ثم تصبح ميزة تتافسية تتميز بها عن غيرها في تحقيق أهدافها بفعالية؛ ممَّا يؤهلها إلى التقدم، بل والبقاء في في بيئة عمل مليئة Su, Guangya, P.373 - بالتغييرات التي قد لا يمكن التتبؤ بها بسهولة 
Mehrabi, Soheila and Siyadat, Sayyed Ali and Allameh, (Sayeed Mohsen, May2013, P.317

\section{: - (الابتكار Innovation}

ويعني قدرة المؤسسة على المبادرة بطرح أفكار مبتكرة، وتثجيعها ودعمها لتحويلها إلى واقع حقيقي ملموس، كاستخدام طرق وأساليب عمل مبتكرة، أو إنتاج وتقديم خدمات مبدعة ومتميزة، وابتكار فرص جديدة لكسب مزايا تتافسية جديدة، تؤهلها لأن تسبق مثيلاتها في كسب رضا العملاء، ومن ثم تكون دومًا في الصدارة (Almahamid, Soud Mohammad, 2013, P.10). 6 - الاعتماد على الكفاءات (Competencies) من المهم أن تعتمد المؤسسة في عملها على أفراد يمتلكون المهارات الأساسية والضرورية للعمل بها، بل ويفهون جيدًا حجم التحديات التي تواجه المؤسسة، ويكونوا على مستوى الكفاءة المطلوبة لمواجهة ذلك، والعمل بأقصى ولى لهوليه جها وبكل تفاني وإخلاص؛ لتحقيق أهداف المؤسسة بفعالية Abesi, Saeed) and Mohammadi, Mahdi and Shafieepur, Davood ,2013 ,

\section{7nitiative المبادرة}

وهي أن يتمتع الأفراد داخل المؤسسة بروح المبادرة في تقديم أفكارهم،

خاصة الجديدة والمبدعة منها، والتي قد تسهم في تطوير أساليب العمل أو الو لهري معالجة النواحي السلبية فيه أو تدعيم النواحي الإيجابية؛ بما يحقق الأفضل للمؤسسة، وأن يبادرون في السعي نحو تحقيقها بشجاعة وثقة وإيجابية، مع العيك الاستعداد لتحمل المزيد من الجهد في سبيل تحقيق ذلك. ثالثًاــ المقومات الأساسية لتحقيق الرشاقة التنظيمية في المؤسسات التعليمية: من أهم المقومات التي قد تسهم في تحقيق الرشاقة التتظيمية في مؤسسات

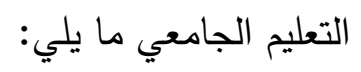

1- مشاركة جميع الأفراد في وضع استراتيجية المؤسسة التعليمية إن وجود إستراتيجية واضحة تتحدد فيها رؤية المؤسسة التعليمية ورسالتها، وأهم الأهداف الإستراتيجية التي تسعى لتحقيقها ليس كافيًا لكى تحقق الرشاقة 
التظظيمية بها، بل من المهم أن تتعاون القيادات الجامعية مع جميع العاملين

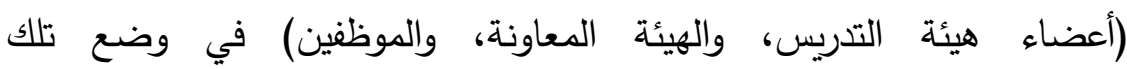
الإستراتيجية، وأن تتيح لهم الفرصة الحقيقية للمشاركة في تحديدها، والأخذ ولذهاء بالآراء الصائبة، وتشجيع الأفكار المتميزة والاستعانة بها؛ ممّا يضمن سعي لهي الجميع بإيجابية، وتفاعلهم وتعاونهم مع القيادات الجامعية نحو تحقيق تلك الك الإستراتيجية بعد إقرارها.

وبالرغم من أهمية وجود إستراتيجية محددة للمؤسسة التعليمية، إلا أنه من إنهان

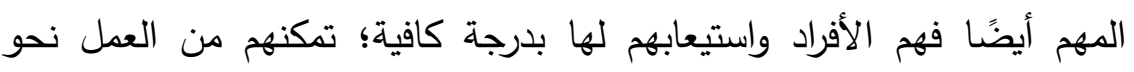
تحقيقها - وذلك من خلال المساهمة الفعالة في وضعها ـ كما أن وضوح الإستراتيجية للجميع يسهم في تقويم الأداء باستمرار على ضودئها.

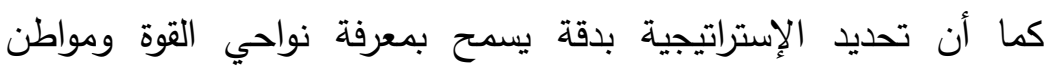

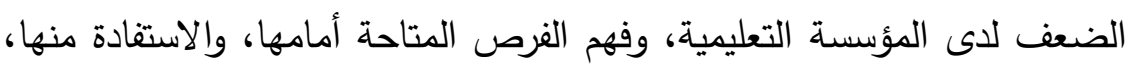
وتحديد التهديدات في بيئتها الخارجية وتحويلها إلى فرص حقيقية، ومن ثم إيجاد مزايا تنافسية جديدة لها، وبذلك تستطيع المؤسسة التعليمية الاستجابة للتغييرات

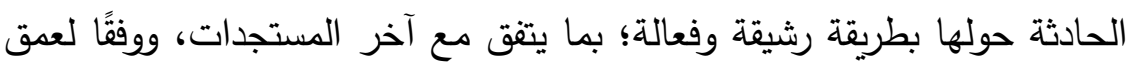

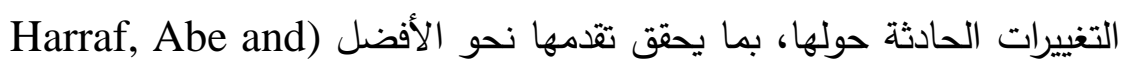
(Others, March/April 2015, P.680 - Hamel, Gary, 2012 2- الاستفادة المُثلى من تكنولوجيا المعلومات:

تعد تكنولوجيا المعلومات أحد أهم الموارد الداعمة للرشاقة التتظيمية؛ لأنها تتيح الفرصة للتعرف على أهم التغيرات أو المستجدات المحلية بل والعالمية في أقصر وقت ممكن، والتوصل إلى أي معلومات، أو الحصول على المعرفة التي

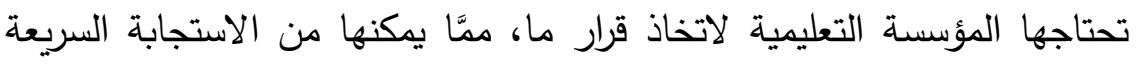
للتغييرات الحادثة حولها، واتخاذ الإجراءات المناسبة في الوقت المناسب.

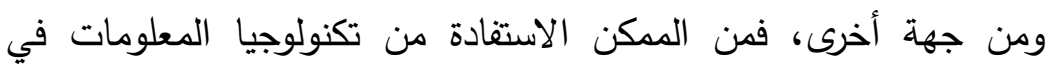
تحقيق الاتصال الفعال بين المستويات الإدارية والأقسام المختلفة داخل المؤسسة الحسن التعليمية الواحدة كافة، أو بينها وبين المؤسسات التعليمية المناظرة والربط بينهم، لإدانه 
وتتيح تبادل المعلومات والخبرات فيما بينها؛ مما يضمن سهولة وانسياب البيانات والمعلومات التي يحتاجها الأفراد في عملهم، ويحقق لهم المزيد من المرونة والتوافق والانسجام والتتاغم بين المستويات الوظيفية المختلفة، ممّا يدعم من لهن

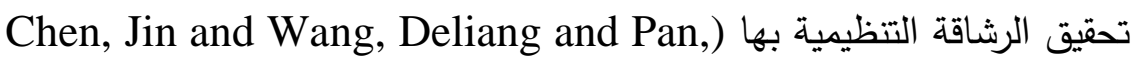
Shan L. , 9July 2011, PP.3-4 -- Yeganegi, Kamran and Saber Zahiri, Mohammad, 3-6 July 2012, P.2544 -- Wendler, Roy and Dresden, Tu, 2014, P.1199).

\section{3- إيجاد هياكل تنظيمية شبكية مرنة:}

إن توفر هياكل تتظيمية شبكية مرنة، تعتمد على التكنولوجيا في التواصل

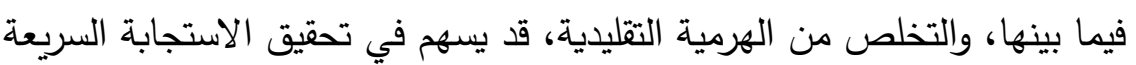

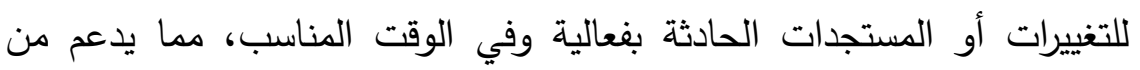
تحقيق الرشاقة التنظيمية بها.

فالهياكل التتظيمية المرنة والرشيقة، تزيد من قدرة المؤسسة على اتخاذ الإجراءات والقرارات المناسبة في الوقت المناسب، وذلك من خلال التعاون

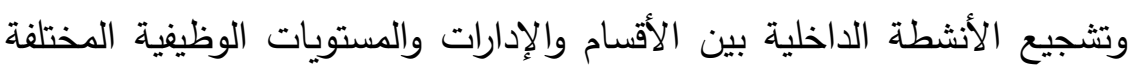
داخل المؤسسة التعليمية، والتي تتيح الفرصة للقيادات الجامعية لمعرفة ما يتم عن قرب في المستويات الوسطى للإدارة، بل والتنفيذية أيضا، وتذليل العقبات التي قد تواجهه لتحقيق الأهداف الإستراتيجية الموضوعة Mehrabi, Soheila) and Siyadat, Sayyed Ali and Allameh, Sayeed Mohsen, May2013, P.318 - Wendler, Roy and Dresden, Tu, 2014,

(P.1200

\section{4- المشاركة في صنع القرار ودعم اللامركزية:}

لكي تتمتع المؤسسات التعليمية بالرشاقة التنظيمية؛ فمن المهم مشاركة مختلف الأفراد من: أعضاء هيئة التدريس، والهيئة المعاونة، والموظفين في صنع القرارات المرتبطة بهم أو المرتبطة بمستقبل مؤسساتهم التعليمية، فوجود تفاعل هيل ديناميكي متبادل بينهم وبين القيادات الجامعية يزيد من فعاليتهم، ويرفع من معنوياتهم، ويضمن الوصول إلى قرار رشيد وسليم، بل وسرعة تتفيذه. 
كما أن إعطاء بعض الصلاحيات للأفراد العاملين في المستويات التنفيذية، كتفويض السلطة وإعطائهم فرصة اتخاذ القرار ، ودعم اللا مركزية؛ يضمن سرعة الاستجابة للتغييرات الحادثة، ومواجهة التحديات بفعالية، وسرعة إنجاز مختلف الأعمال المطلوبة منهم بطريقة أكثر مرونة.

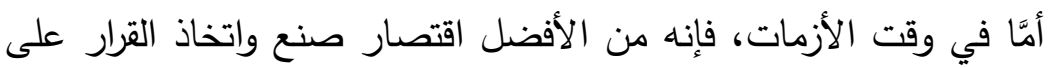

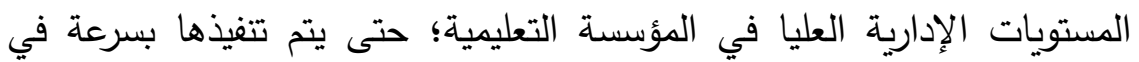

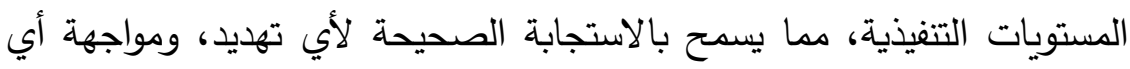
مشكلة خطيرة بطريقة سليمة، والتي لن يستطيع الأفراد في المستويات التنفيذية على اتخاذ القرار المناسب لمواجتها في الوقت المناسب. ومن ثم يتضح أهمية دعم اللا مركزية في المستويات التنفيذية في الأمور العادية؛ لتحقيق سرعة التعامل، والاستجابة لأي تغيرات، وتحقيق فعالية الأداء،

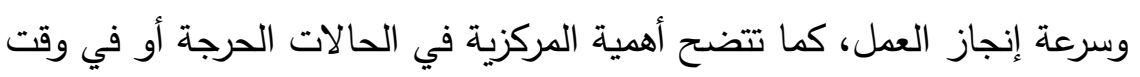
Yaghoubi, Nour Mohammad and Sarabandi,) Parisa الأزمات and Banihashemi, Seyyed Ali, 2011, P.251 -- Mehrabi, Soheila and Siyadat, Sayyed Ali and Allameh, Sayeed Mohsen, May2013, P.318 -- Harraf, Abe and Others, (March/April 2015, P.679 5- كفاءة الأفراد بالمؤسسات التعليمية:

إن الأفراد الذين يعملون في المؤسسات التعليمية، لابد أن يكونوا على قدر

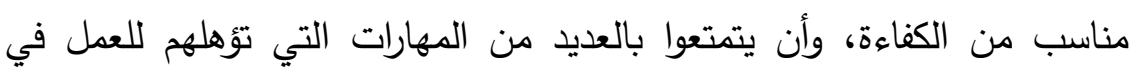

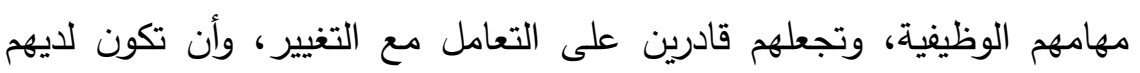

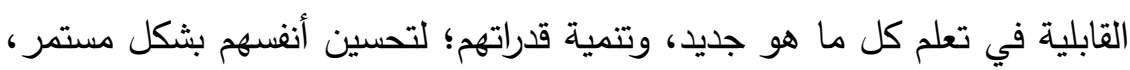

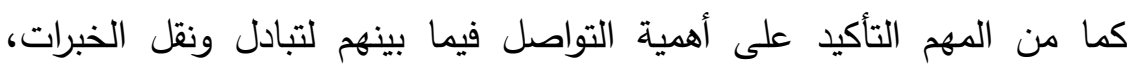
وتعزيز قدراتهم نحو تحمل المسئولية.

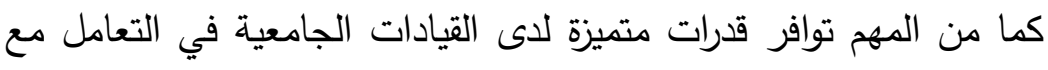

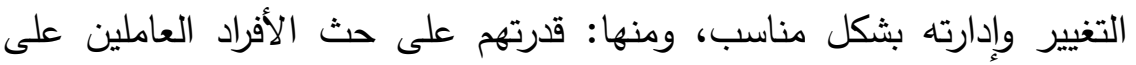
مواجهة التغيير بدلًا من مقاومته، وتوفير السبل والأساليب التي تساعدهم على ونى 
مواكبة التحديات كافة، والاستفادة منها لصالح المؤسسة التعليمية، والاهتمام بتحقيق احتياجاتهم؛ لتحقيق رضاهم الوظيفي الذي سيؤثر إيجابيًا على سرعة

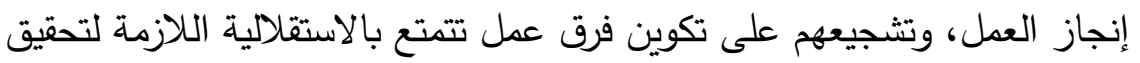
أهداف المؤسسة التعليمية بدلًا من تركيز الجها على على استيفاء العديد من الأمور

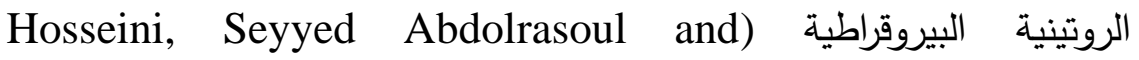
Others,2013, P.2936 - Wendler, Roy and Dresden, Tu, 2014, (PP.1199-1200

6- إتاحة المناخ الداعم للابتكار، وتجريب الأفكار الجديدة والمتميزة: لابد من توافر ثقافة تنظيمية داعمة للابتكار، وتشجع على المبادرة والثقة في تقديم كل ما هو جديد دون تردد أو خوف مبالغ فيه من المخاطرة، فالابتكار

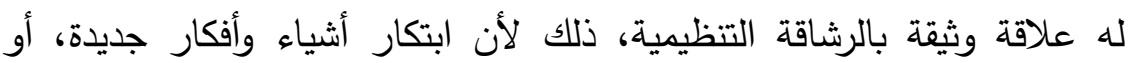

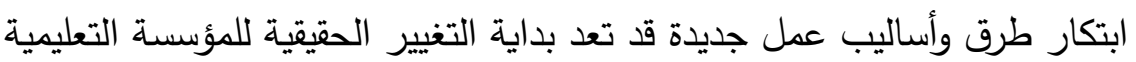
نحو الأفضل، واعتبارها فرصًا قد تتحول إلى مزايا تتافسية تتمتع بها المؤسسة، وتجعلها قوية في ظل التحديات التنافسية المحلية والعالمية. كما أن استحداث حلول جديدة ومبتكرة للمشكلات القائمة، أو استحداث عمليات وطرق عمل جديدة يحتاج إلى التجريب. فمن المهم تشجيع ثقافة تجريب الأفكار الجديدة مع تقويمها باستمرار، من خلال دعمها إذا أثبتت فعاليتها،

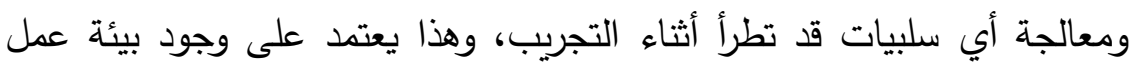
مشجعة للتغيير نحو الأفضل وداعمة للابتكار مaghoubi, Nour) Mohammad and Sarabandi, Parisa and Banihashemi, Seyyed Ali, 2011, P.252 -- Harraf, Abe and Others, March/April (2015, P.678 وعلى ضوء ما سبق، فقد تم التعرف على مفهوم الرشاقة التظظيمية، وأهم المصطلحات المرتبطة به، وعناصرها وأهم المقومات التي قد تسهم في تحقيقها

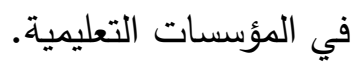


المحور الثاني ـ القدرة المؤسسية في التعليم الجامعي المصري: وتوضحه الدراسة، كما يلي:

أولًا- مفهوم القدرة المؤسسية في التعليم الجامعي المصري:

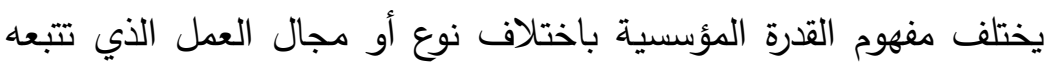

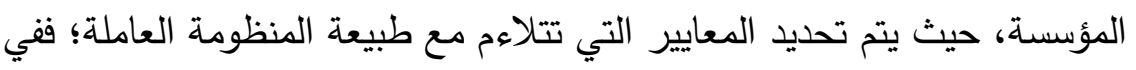
الولايات المتحدة الأمريكية، وضعت وكالة الولايات المتحدة للتمية الدولية (USAID: United State Agency International Development) مفهوم تتمية القدرة المؤسسية والبشرية على أنها: التثييم المستمر للأداء التتظيمي الكلي للمؤسسة، وذلك بالاعتماد على مدخل النظم؛ بهدف تقديم حلول تتظيمية مناسبة لتقليص الفجوة بين الأداء الفعلي والأداء المتوقع من المؤسسة. (USAID, October 2010, P.6)

كما أنها وضعت ثمان خطوات محددة لتحقيقها، وهي كالتالي: (USAID,

October 2010, P.8) - الخطوة الأولى: وصف مشكلات الأداء التظظيمي للمؤسسة، وذلك من

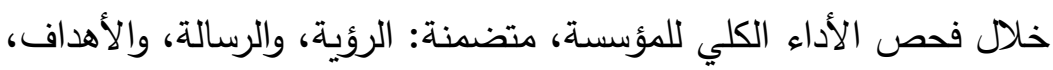
والإستراتيجيات، والثقافة التنظيمية لها، وتوقعات العملاء، وبيئة العمل الخارجية منها. - الخطوة الثانية: وصف الأداء المرغوب به، ووضعه في صورة معايير وطنية أو دولية قابلة للقياس.

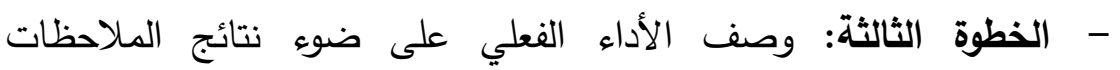
والمقابلات مع العاملين بالمؤسسة، والعملاء، ومراجعة التقارير والوثائق المتعلقة بها. - - الخطوة الرابعة: وصف وقياس الفجوة في الأداء، من خلال توضيح الفرق بين الأداء المطلوب والأداء الفعلي. - - الخطوة الخامسة: تحديد الأسباب الأساسية التي تسببت في إحداث الفجوة، واعتبارها بمثابة العوامل المؤثرة على أداء العاملين في المؤسسة. 
- الخطوة السادسة: طرح الحلول المناسبة لعلاج أسباب حدوث الفجوة، وترتيبها طبقًا لأهميتها، ومدى مناسبتها من حيث التكلفة والجدوى ومعايير أخرى.

- الخطوة السابعة: تطبيق الحلول المختارة بدعم من إدارة المؤسسة وشركائها، وبكل شفافية وإخلاص.

- - الخطوة الثامنة: مراجعة وتقييم الأداء بعد تطبيق الحلول المختارة باستمرار ، ثم إعادة قياس الفجوة في الأداء مرة أخرى؛ لمعرفة مدى تأثير الحلول المطبقة على الأداء.

African أمَّا المنظمة الأفريقية لمؤسسات الفحص المحاسبي العليا Organization of Supreme Audit Institutions (AFROSAI) تعد منظمة رقابية تهتم بتتمية قدرتها المؤسسية لتمكين ودعم الأجهزة الرقابية الأعضاء التابعين لها، وقد عرفت مفهوم بناء القدرة المؤسسية على أنه:

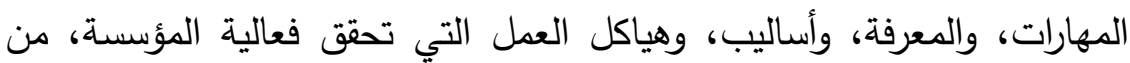
خلال استثمار نقاط القوة بها، ومعالجة مواطن الضعف أو الثغرات التي تشوبها (African Organization of English-speaking Supreme Audit Institutions, December 2010). وقد تضمنت خمسة مجالات لبناء القدرة المؤسسية، يتم تطويرها على ضوء خمسة مستويات، وتلك المجالات هي: African Organization of) English-speaking Supreme Audit Institutions, December (2010 Independence and Legal الأول: الاستقلال والإطار القانوني .Framework - Organisation and Management الثاني: المؤسسة والإدارة -

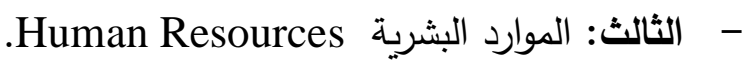
Audit Standards and الرابع: معايير الفحص المحاسبي والمنهجية .Methodology

- مامس: الاتصالات وإدارة أصحاب المصلحة Communication and .Stakeholder Management 
وحيث إن الدراسة الحالية تركز على تحسين القدرة المؤسسية في مؤسسات

التعليم الجامعي المصري، والتي تسعى حاليًا لتحقيق الجودة بها، من خلال العمل على تحقيق المعايير التي تم تحديدها من قبل الهيئة القومية لضمان جودة التعليم والاعتماد، والتي تعد القدرة المؤسسية أحد المحاور الأساسية المهمة لتحقيق الجودة، فقد تبنت الدراسة الحالية مفهوم القدرة المؤسسية الذي حددته الهيئة، والذي تم توضيحه سابقًا في هذه الدراسة، وذلك في بند (مصطلحات الدراسة).

\section{ثانيًا معايير القدرة المؤسسية بالتعليم الجامعي المصري:}

تتضمن معايير القدرة المؤسسية في مؤسسات التعليم الجامعي المصري، ثمانية معايير أساسية هي: التخطيط الإستراتيجي، والهيكل التظيمي، والقيادة والحوكمة، والمصداقية والأخلاقيات، والجهاز الإداري، والموارد المالية والمادية، والمشاركة المجتمعية وتتمية البيئة، والتقويم المؤسسي وإدارة الجودة. (الهيئة القومية لضمان جودة التعليم والاعتماد، أبريل 2008م، ص2)، ونظرًا لطبيعة ودية الدراسة الحالية، فقد اكتقت الدراسة بالتركيز على ثلاثة معايير فقط، والتي يمكن تحسينها وتطويرها على ضوء فكر الرشاقة التظيمية، وهي كما يلي: 1

من المهم أن يكون للمؤسسة التعليمية خطة إستراتيجية متكاملة واقعية وقابلة للتنفيذ، توضح فيها الصورة المستقبلية التي تسعى إلى تحقيقها، من خلال وضع رؤيسة واضحة، ورسالة محددة، وأهداف إستراتيجية دقيقة.

ويتم وضع الخطة الإستراتيجية من خلال: تحديد نقاط القوة، ومواطن الضعف المتعلقة ببيئة المؤسسة التعليمية الداخلية، وكذلك تحديد الفرص المتاحة، والتهديدات المتعلقة ببيئتها الخارجية. ومن خلال هذا التحليل تتضح ملامح المؤسسة التعليمية، وخصائصها المميزة، ومسئولياتها نحو المجتمع، وارتباطها بالخطة الإستراتيجية للجامعة التابعة لها.

كما على المؤسسة التعليمية وضع رؤيسة واضحة، يساهم في وضعها الأطراف المعنية كافة، وتترجم في رسالة دقيقة ومحدة، مع الاهتمام بتوفير 


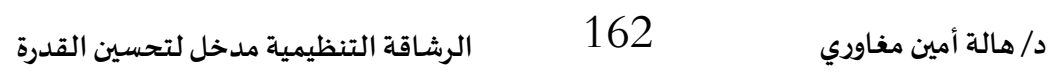

آليات لمراجعتها باستمرار، ومن ثََّّ وضع الأهداف الإستراتيجية على ضوئها.

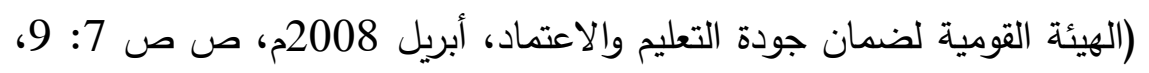
$(15: 18$

\section{2- 2 - الهيكل التنظيمي:}

لابد أن يشتمل الهيكل التنظيمي على كل الوحدات والأقسام والإدارات في المؤسسة التعليمية، مع تحديد شكل العلاقات الوظيفية فيما بينها، والتي تسهم في تحديد أدوار ومسئوليات كل كيان وظيفي فيها، مع وضع توصيف تُونيف وظيفي دقيق، يحدد المهام الوظيفية لكل عنصر بشرى داخل كل كيان وظيفي؛ لضمان الثفافية

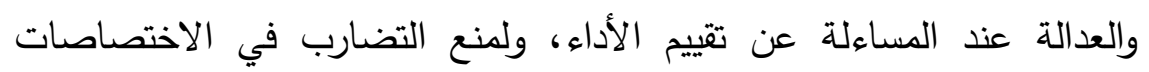

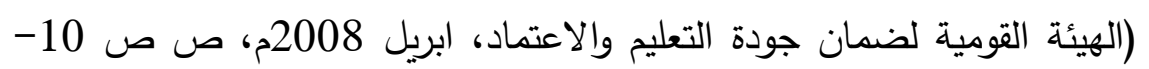

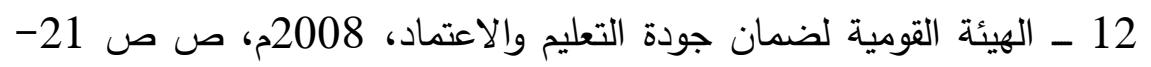

كما من المهم أن يشمل الهيكل التنظيمي جميع الأنشطة التي تقدمها

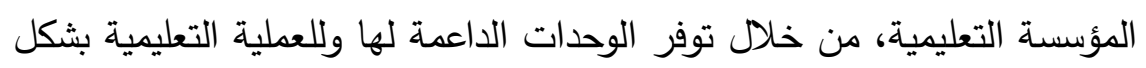
عام، كما يجب أن " يتصف تشكيل الهيكل التظيمي بالثمولية والرشاقة والمرونة، أي القابلية للتغيير في ضوء التقويم المستمر لكفاءته وفاعليته" (الهيئة

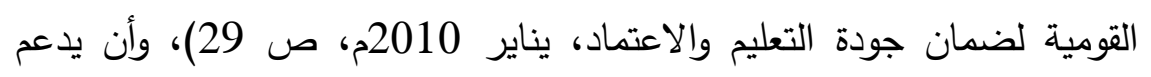
التظظيم الشبكي الذي قد يسمح بإتمام الأعمال وإنجاز المهام المطلوبة في أقصر

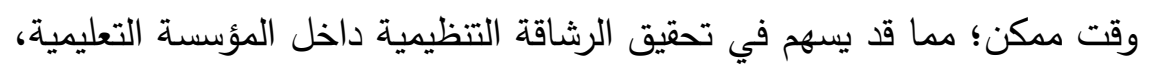

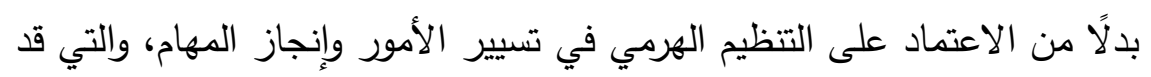
تتم في فترة زمنية أطول وبشكل أبطأ. 3- القيادة وإلحوكمة

إن القيادة الواعية بحجم التحديات التي تواجه المؤسسات الجامعية، تجعلها قادرة على شحذ جميع الهمم والطاقات الإبداعية لدى العاملين داخل المؤسسات

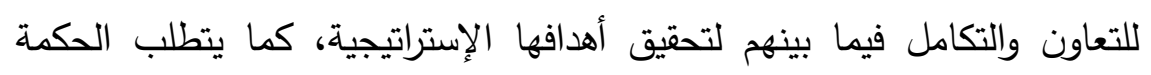
والقدرة على الاستخدام الأمثل للموارد المتاحة بها. 
ومن أهم المؤشرات التي تتضمن معيار القيادة والحوكمة، القدرة على

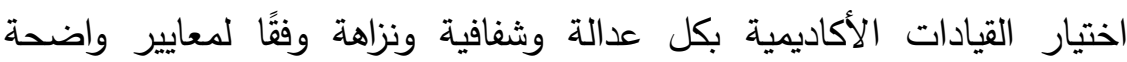
ومحددة، وبما يحقق صالح العملية التعليمية، بالإضافة إلى اتباع نمط قيادي

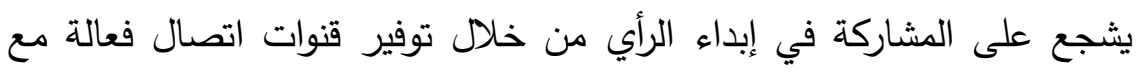
الجميع، بما يضمن القدرة على اتخاذ قرارات سليمة مدعمة بمشاركة الجميع، وأن تسهم المؤسسة التعليمية بنشر ثقافة الثفافية والمحاسبية مع محاولة تفعيلها. كما تتضمن مساهمة المجالس الرسمية في مناقشة واتخاذ قرارات تدعم العملية التعليمية وتسهم في تطويرها، مع الاهتمام بتقديم التدريب اللازم للقيادات

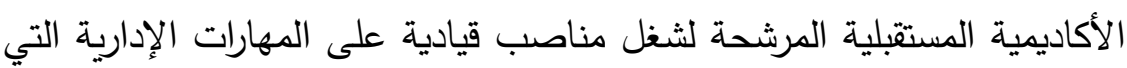
تساعدهم في أداء مهامهم الوظيفية الجديدة بفعالية، وأن تتوفر قواعد بيانات موثقة ورسمية تضم مختلف الإدارات والأقسام والوحدات، وأن يتم تحديثها باستمرار، وذلك لدعم القرارات بأسانيد ومعلومات قانونية وإدارية صحيحة، كما من المهم إتاحة المعلومات بسهولة لجميع العاملين داخل المؤسسة التعليمية، وتوفير الدعم اللازم لتطوير نظم الجودة الداخلية بها، مع مناقشة طرق تنمية الموارد الذاتية للمؤسسة التعليمية، وذلك من خلال توطيد العلاقة بينها وبين

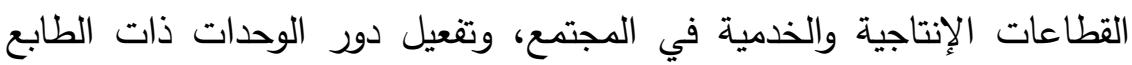
الخاص لتحقيق ذلك، مع الاهتمام بالتقييم المستمر لضمان جودة وكفاءة المؤسسية التعليمية، مع احترام الآراء والمقترحات المقدمة لتطويرها نحو بهو

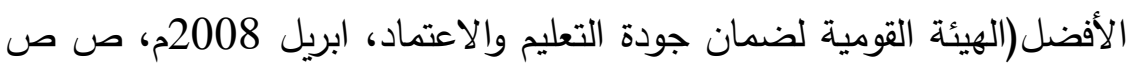

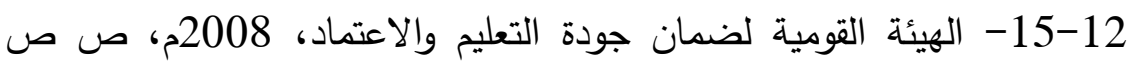

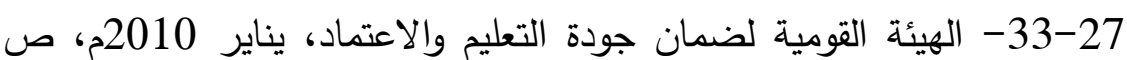




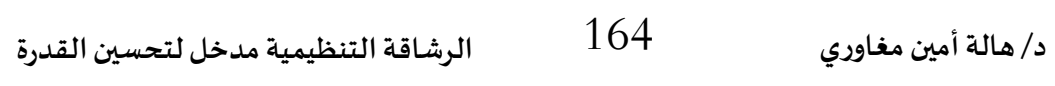

المحور الثالث ـ توصيات وآليات إجرائية مقترحة لتحسين القرة المؤسسية بالتعليم الجامعي المصري على ضوء مدخل الرشاقة التظيمية: ومن أهم التوصيات المقترحة التي قد تسهم في تحسين القدرة المؤسسية في التعليم الجامعي المصري، على ضوء مدخل الرشاقة التظيمية ما يلي:

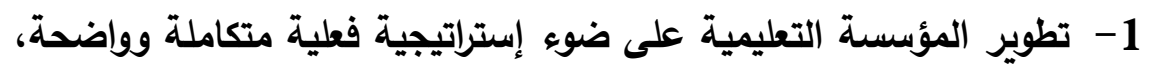
ومن الآليات المقترحة لتحقيق ذلك ما يلي: أ- مشاركة جميع الأقسام والإدارات والوحدات العاملة في المؤسسة التعليمية لهية

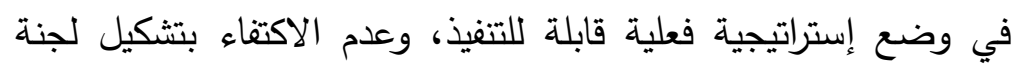

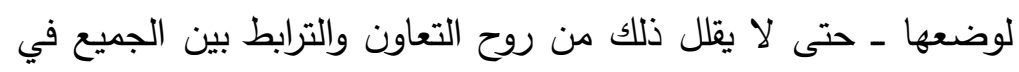

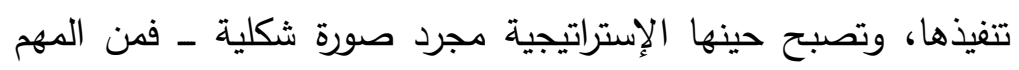
أخذ مختلف الآراء والمقترحات في الاعتبار؛ مما يزيد الإحساس بالانتماء التنظيمي للمؤسسة، ومن ثََّّ يتفاعلون مع القيادة في تحقيقها.

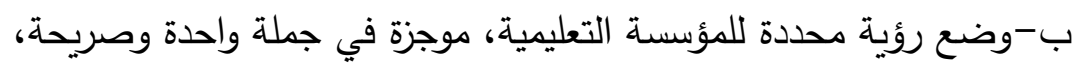

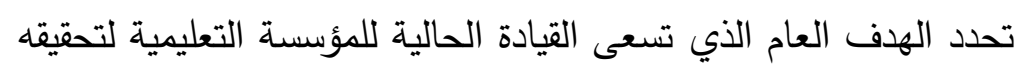
في فترة زمنية محددة؛ مما قد يسهم في شحذ الطاقات وتوجيهها نحو لتونه

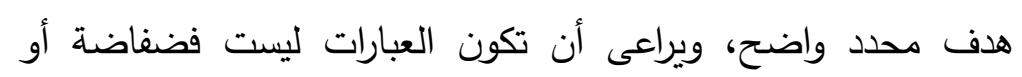
رنانة، وألّا تحمل أكثر من معنى. ج-ترجمة الرؤية في رسالة محددة النقاط، وأن تكون عباراتها أكثر عملية أو إجرائية؛ حتى يستطيع جميع الأفراد في المؤسسة التعليمية فهمها ونيا

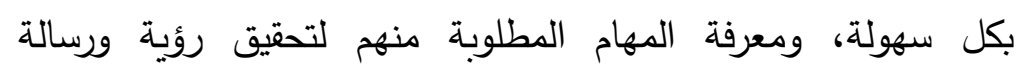
المؤسسة التعليمية. د- اعتبار جميع الأقسام والإدارات والوحدات بمثابة فرق عمل تعمل سويًا

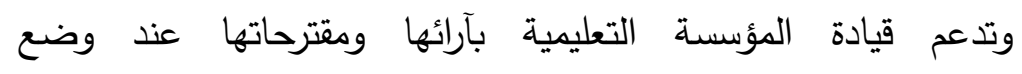
الإستراتيجية، وخاصة عند تحديد نقاط القوة ومواطن الضعف الداخلية مع تقديم مقترحات لتدعيم نقاط القوة ومعالجة مواطن الضعف، وكذلك ولك تحديد الفرص المتاحة والتهديدات الخارجية التي تواجه المؤسسة 
التعليمية، مع تقديم مقترحات لكيفية الاستفادة من تلك الفرص لدعمها، وإيجاد مزايا تنافسية جديدة لها على الساحة التعليمية، وكيفية مواجهة التهديدات، وتحويلها إلى فرص يمكن الاستفادة منها مستقبلًا. هـ-وضع خطط إجرائية تنفيذية على ضوء نتائج التحليل البيئي الداخلية والخارجية للمؤسسة التعليمية، لتقليل الفجوة بين الأداء الفعلي والأداء المأمول للنهوض بالمستوى العلمي والتعليمي بها. و - مراجعة وتقييم مستوى الأداء دوريا، مع توضيح طرق ليعي التقييم المستخدمة، وتعديل أساليب وطرق العمل بناء على نتائجها. 2- استثمار تكنولوجيا المعلومات في تحقيق مرونة الهيكل التظيمي بالمؤسسة التعليمية، ومن الآليات المقترحة لتحقيق ذلك، ما يلي: أ- ربط جميع أقسام وإدارات ووحدات المؤسسة التعليمية بشبكة معلوماتية

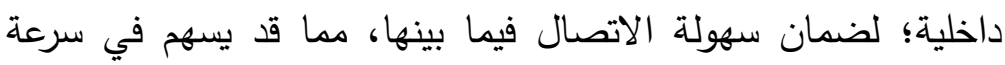
تبادل التقارير إلكترونيًّا، كما قد يسهم في اتخاذ القرار المناسب بالسرعة

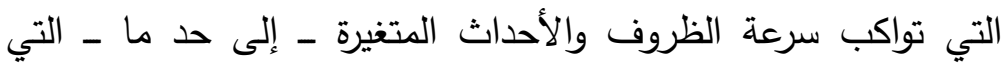
تفرضها بيئة العمل. ب-تأسيس قاعدة بيانات متاحة لجميع الأفراد داخل المؤسسة التعليمية، وألّا تكون حكرًا على قياداتها فقط؛ مما ييسر أداء العمل في المستويات التهات التتفيذية على أسس وحقائق سليمة، مما قد يؤدى إلى إنجاز العمل فئل فئل بالسرعة المطلوبة، كما قد يسهم في دعم عملية صنع القرار على الى

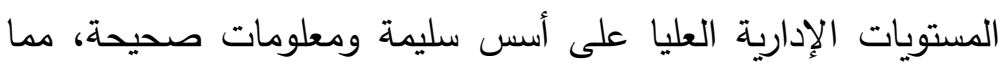
يضمن اتخاذ قرار رشيد في الوقت المناسب.

ج-وجود شبكة معلوماتية تتيح فرص التواصل الشبكي بين المستويات

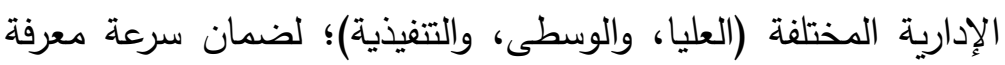

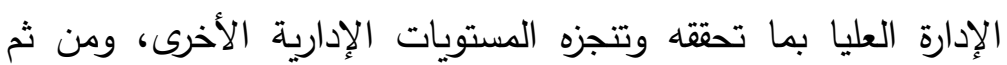
دعمها وتذليل العقبات التي قد تواجهها، مما قد يسهم في تحقيق المزبد 
من الرشاقة التتظيمية، ومن ثم التخلص من سلبيات التنظيم الهرمي، والربط بينهم بشكل أكثر فعالية. د- إن وجود الشبكة المعلوماتية قد تسهم في تحقيق الرقابة على مدى تقدم العمل من خلال ما توفره الشبكة من فرصة التواصل الشبكي بين مختلف الأقسام والإدارات والوحدات العاملة بالمؤسسة التعليمية. هـ -أن تتفاعل الإدارة العليا للمؤسسة التعليمية مع مختلف الأفراد في لإداته

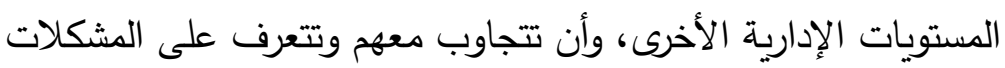
التي تواجههم على أرض الواقع دون تضخيم أو تهوين لها، وتذلل لهم

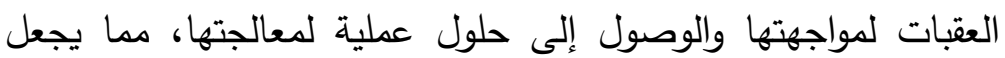
المؤسسة التعليمية أكثر رشاقة تتظيميا. 3- اتباع أساليب تشاركية حديثة في قيادة المؤسسات التعليمية؛ مما قد يسهر تُشيه

في تحقيق الحوكمة بها، ومن الآليات المقترحة لتحقيق ذلك، ما يلي:

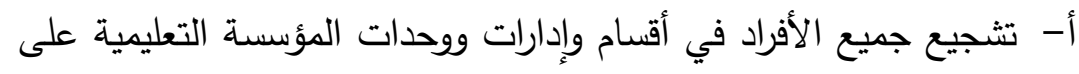

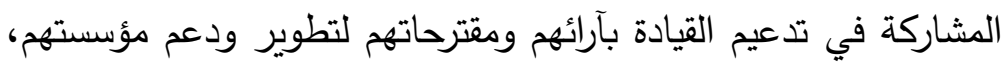
وإتاحة الفرصة للاستماع للنقد البناء والاستفادة منه في صنع القرار

$$
\text { وتحسين أداء العمل. }
$$

ب-أن تتبنى قيادة المؤسسة التعليمية الأفكار والمقترحات المتميزة من

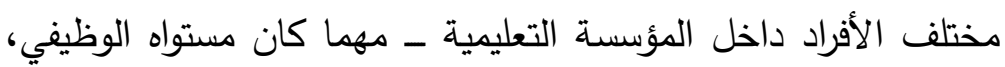
فالعبرة بمستوى تميز الأفكار وجدواها، وليس بمستوى الفرد الوظيفي -

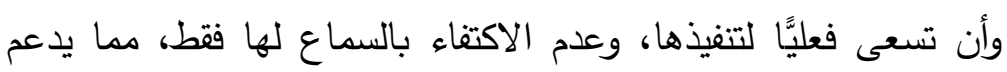

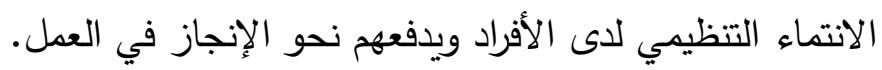
ج-أن تستخدم القيادة العليا بالمؤسسة التعليمية أسلوب تفويض السلطة الإنة

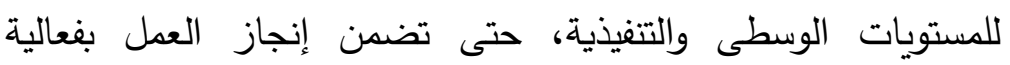

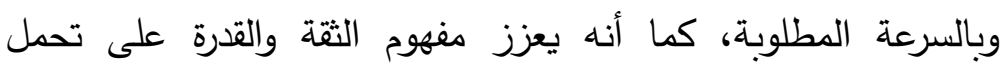
المسئولية لدى هؤلاء الأفراد، مما يدفعهم لبذل المزيد من الجهد لإنجاز

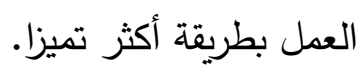


د- أن تتيح القيادة بالمؤسسة التعليمية الفرصة لتجريب الأفكار الجديدة

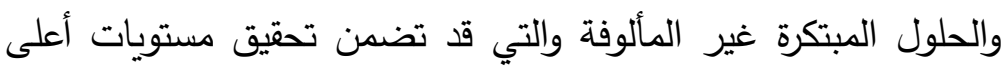
من الإنجاز، ودعم أصحاب تلك الأفكار، وتذليل العقبات أمامهم للرفع من مستوى المؤسسة التعليمية. هـ - إعداد دليل تفصيلي يتضمن توصيفًا دقيقًا للمهام والممارسات الوظيفية المطلوبة من كل فرد عامل داخل المؤسسة التعليمية ــ مهما كان مستواه الوظيفي - حتى يسهل تقويمه على ضوئها، ومن ثم يمكن محاسبته ومساءلته عند تقصيره، كما يمكن إثابته إذا أدى مهامه بفعالية وإتقان. و - أن توفر قيادة المؤسسة التعليمية الشفافية عند صنع واتخاذ القرارات المختلفة، مع إمكانية إطلاع الأفراد عليها.

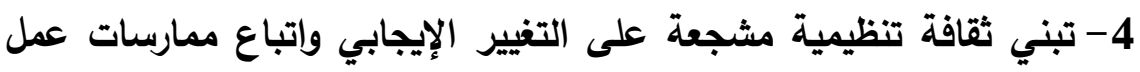
جديدة وفعالة تواكب العصر، والتخلي عن أساليب العمل التقليدية، ومن التهاب الآليات المقترحة لتحقيق ذلك ما يلي: أ- تدريب الأفراد طبقًا لكل مستوى وظيفي دوريًا في مختلف الأقسام والإدارات والوحدات في المؤسسة التعليمية؛ لضمان ارتفاع مستوى كفاءة الأفراد، واطلاعهم على كل ما هو جديد في مجال عملهم، وتدريجهم على كيفية ممارسة العمل بأساليب جديدة مختلفة عن الأساليب التقليدية، والتي تسعى قيادة المؤسسة التعليمية إلى استخدامها والتغيير إليها. ب-إعداد دليل يتضمن مختلف الجوانب القانونية والمالية والإدارية التي قد تسهم في معرفة كل فرد عامل داخل المؤسسة التعليمية بحقوقه وواجباته، والامتيازات التي سينالها في حالة إنجاز عمله بالطريقة المطلوبة، والعقوبات التي ستقع عليه في حالة إهماله أو إخلاله لمهامه الوظيفية. 
ج- إثابة كل فرد مجتهد ومتميز في عمله، وتقدير أفكاره ومقترحاته المتميزة

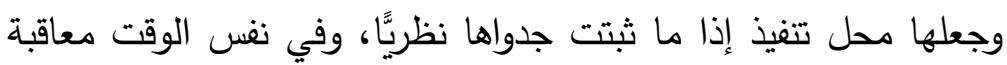
كل فرد متقاعس عن عمله، ولا يؤدي مهامه الوظيفية على الوجه المطلوب.

د- تهيئة الأفراد للتغيير عند تطبيق ممارسات عمل جديدة، من خلال تفهم

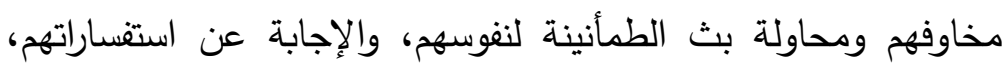
وإعطاء الوقت الكافي لفهم الأمر بشكل كامل قبل تتفيذه، ومن ثم الاستفادة من مقترحاتهم وحلولهم لأي جوانب سلبية قد تظهر في لاعتي المستقبل عند تنفيذها.

هـ - تحقيق الرضا الوظيفي للأفراد العاملين، وإشعارهم بالأمان والثقة والاحترام والتقدير، والاهتمام بمناسباتهم الاجتماعية، وتوطيد العلاقة بين

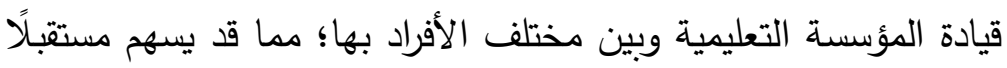
في سرعة إنجاز العمل بمفهوم الأسرة الواحدة.

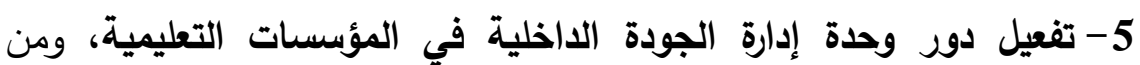
الآليات المقترحة لتحقيق ذلك، ما يلي: أ- اهتمام القائمين على وحدة إدارة الجودة الداخلية في المؤسسة التعليمية بالاطلاع على نظم التعليم الجامعية المتميزة في الدول المتقدمة، والاستفادة منها في تطوير المؤسسة التعليمية المماثلة لها، لمواكبة

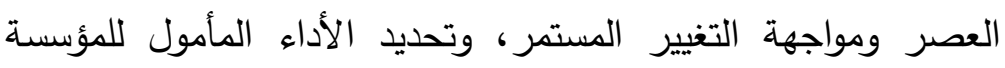
التعليمية على ضوئها، واتخاذ القرارات اللازمة بالتعاون مع العاملين داخل المؤسسة التعليمية وبدعم قياداتها، وأن لا يقتصر دورهم على بعلى والى مجرد تجميع أوراق وتقارير رسمية جامدة من مختلف أقسام وإدارات

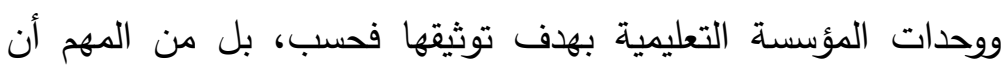
يرتقي دورهم إلى تأسيس نظام متميز رشيق، يسهم في تحقيق أهداف المؤسسة التعليمية بفعالية ويسر وبالسرعة المطلوبة. 
ب-أن تهتم وحدة إدارة الجودة الداخلية في المؤسسة التعليمية بالاطلاع على المؤسسات التعليمية المناظرة لها في مختلف الجامعات المصرية؛ لتبادل الخبرات، وتحديد المستوى الحقيقي الفعلي للمؤسسة وسط مثيلاتها، وتحديد درجة تفاعلها مع المجتمع الخارجي وإفادتها لله، ومن وندي ثم إطلاع مختلف الأفراد وقيادة المؤسسة التعليمية بذلك؛ لاتخاذ القرارات اللازمة لتطوير وتحسين مستواها المحلي. ج- أن تكون وحدة إدارة الجودة الاخلية في المؤسسة التعليمية بمثابة وحدة ولئ أساسية لتقييم الأداء الكلي؛ وذلك بإعداد تقارير دورية عن مستوى أداء

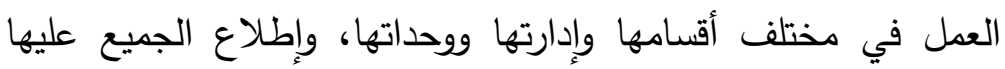
ومناقشتها، وتحديد الخطوات الإجرائية القادمة نحو التغيير والتحسين والتطوير د- أن تصبح وحدة إدارة الجودة الداخلية بمثابة وحدة استثعار التغيير في

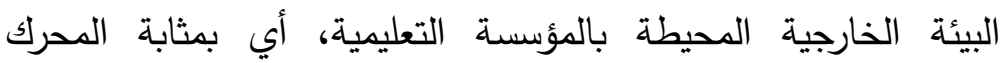
الأساسي للعمل نحو التطوير واستباق الأمور ، ومقصد مختلف الأفراد

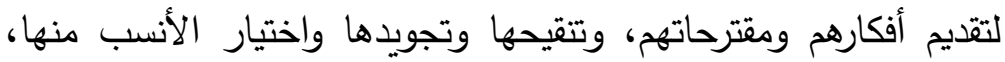
ومناقشته مع مختلف الأقسام والإدارات والوحدات والقيادات، ثم اتخاذ وناذ القرارات المناسبة لذلك. هـ اهتمام وحدة إدارة الجودة الداخلية في المؤسسة التعليمية بربط جميع

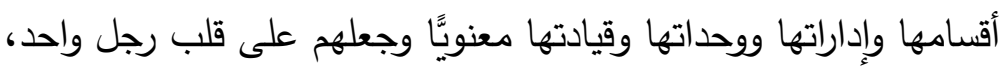
في تجميع آرائهم ومقترحاتهم نحو التغيير وكيفية تتفيذه وإدارته.

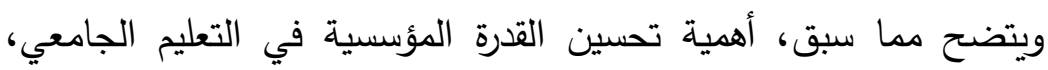
وجعل مؤسساته رشيقة وخفيفة الحركة في تعاملها مع متغيرات العصر، وجعلها كيانًا واحدًا يعمل سويًا بفكر جديد ومتجدد؛ لمواجهة مختلف التحديات.

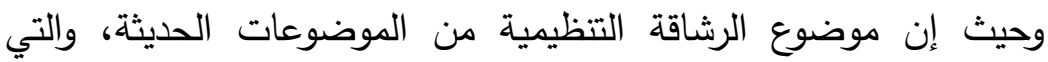
تحتاج إلى المزيد من الدراسة والبحث، فمن الممكن اقتراح بعض الموضوعات 
التي قد تقتح المجال أمام المزيد من الأبحاث والدراسات العربية في المستقبل،

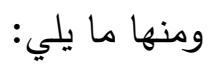

1- واقع الرشاقة التنظيمية في المؤسسات التعليمية، بأن يتم إجراء دراسة ميدانية للكثف عن واقع الرشاقة التنظيمية في إحدى المؤسسات التعليمية التابعة لوزارة التعليم العالي، وذلك على ضوه عند التهاصر الرشاقة التظيمية وأهم مقوماتها.

2- تحقيق مقومات الرشاقة التظيمية في إدارة التعليم قبل الجامعي في

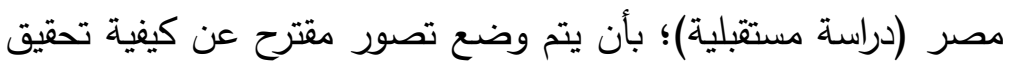

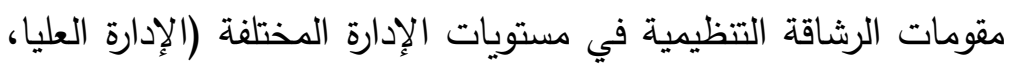
والوسطى، والتتفيذية) في التعليم قبل الجامعي، على ضوه رأي الخبراء ذوي الاهتمام بالتعليم قبل الجامعي، وذلك باستخدام أحد أساليب الدراسات المستقبلية كأسلوب دلفاي (Delphi Technique). 


\section{مراجع الدراسة}

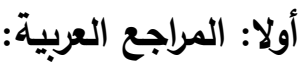

1- ابن منظور (د.ت): " لسان العرب"، المجلد الرابع، الجزء 36، القاهرة، دار

المعارف.

2- أحمد مرعي هاشم (2009م): " متطلبات بناء القدرات المؤسسية للمنظمات غير الحكومية"، رسالة ماجستير غير منشورة، كلية الخدمة الاجتماعية،

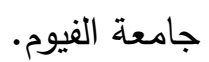

3- البنك الدولي ومنظمة التعاون والتتمية في الميدان الاقتصادي (2010م): " التعليم العالي في مصر"، من سلسلة (مراجعات لسياسات التعليم الوطنية).

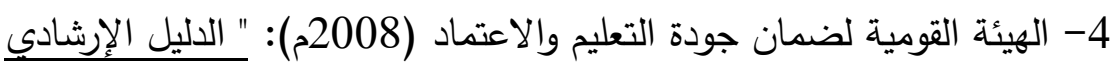
لتوفير المتطلبات اللازمة لضمان جودة التعليم والاعتماد لمؤسسات التعليم العالي"، الإصدار الأول، جمهورية مصر العربية.

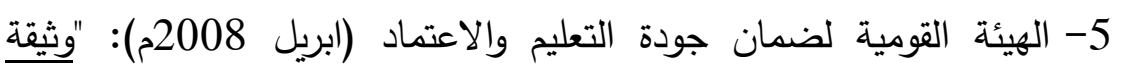
المعايير والممارسات التطبيقية ـ مؤسسات التعليم العالي"، جمهورية مصر والئه العربية.

6- الهيئة القومية لضمان جودة التعليم والاعتماد (أغسطس 2009م): "دليل الاعتماد لمؤسسات التعليم العالي"، جمهورية مصر العربية، الإصدار الثاني.

7- الهيئة القومية لضمان جودة التعليم والاعتماد (يناير 2010م): " الوثيقة

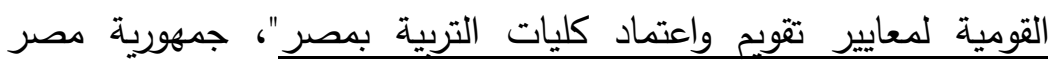
العربية.

8- الهيئة القومية لضمان جودة التعليم والاعتماد (أكتوبر 2013م): " تقرير عن إنجازات الهيئة في السنوات (2008-2013) ورؤبتها نحو التطوير"، جمهورية مصر العربية. 
9- كريمة عيد كامل (2009م): " برنامج مقترح لدور الخدمة الاجتماعية في

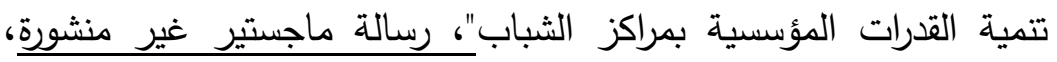
كلية الخدمة الاجتماعية، جامعة الفيوم.

10-محمد محروس شحاتة سلامة (2012م): "قياس القدرة المؤسسية وفعالية الإنتاج لإجراء التحسين المستمر وضمان جودة الأداء في المؤسسات الصحفية"، رسالة دكتوراه غير منشورة، كلية الفنون التطبيقية، جامعة

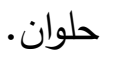

11-محمد موفق أحمد المكي (1-4 نوفمبر 2009م): " هل يمكن للستة سيجما الرشيقة أن تساعد في تحسين أداء القطاع العام في العالم العربي؟" العئ،

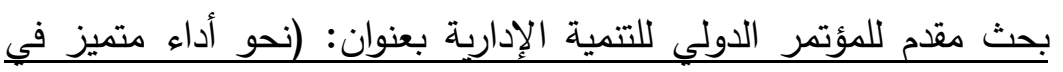
القطاع الحكومي)، المملكة العربية السعودية، معهد الإدارة العامة. 12-منير بعلبكي (1995م): " المورد"، بيروت، دار العلم للملايين. 13-هدير محمد عبد الله (2015م): " التخطيط الإستراتيجي كمعيار للقدرة المؤسسية في المكتبات الجامعية بمصر - دراسة ميدانية"، رسالة ماجستير غير منشورة، كلية الآداب، جامعة القاهرة.

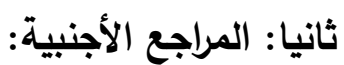

1- Abesi, Saeed and Mohammadi, Mahdi and Shafieepur, Davood (2013): "The Role of Organizational Agility Capabilities in the Successful Performance of the National Production", In (World of Science Journal).

2- African Organization of English-speaking Supreme Audit Institutions (December 2010): "Institutional Capacity Building Framework", at the website:

(http://afrosai-e.org.za/sites/afrosaie.org.za/files/ICBFGuideline.pdf).

(Date: 30/11/2015)

3- Aitken, James and Christopher, Martin and Towill, Denis: "Understanding, Implementing and Exploiting Agility and Leanness", at the website: (http://www.som.cranfield.ac.uk/som/dinamiccontent/research/Iscm/understanding_implementing_exploitin g.pdf) 
(Date: $15 / 11 / 2015$ )

4- Alhadid, Anas Y. and Abu-Rumman, As'ad (March2015): "Effective Determinations on Organization Agility Practices: Analytical study on Information Technology Organization in Jordan", In (International Review of Management and Business Research), Vol.4, Issue 1.

5- Almahamid, Soud Mohammad (2013):" E-government System Acceptance and Organizational Agility", In (International Journal of Information, Business and Management), Vol.5, No.1.

6- Chen, Jin and Wang, Deliang and Pan, Shan L. (9July 2011): " Understanding Organizational Agility Development for Government- A Process Model of Resource Configuration", $\underline{\text { In }}$ (Pacific Asia Conference on Information Systems), Association for Information Systems.

7- Community College Research Centers (January 2015): "Increasing Institutional Capacity to Respond to Performance Funding", Teachers College, Columbia University.

8- Erande, Ameya S. and Verma, Alok K.( 2008): " Measuring Agility of Organizations - Acomprehensive Agility Measurement Tool", In (IAJC - IJME International Conference), at the website:

(http://citeseerx.ist.psu.edu/viewdoc/download?doi=10.1.1.56 $\underline{6.1672 \& \text { rep }=\text { rep } 1 \& \text { type }=\text { pdf) }}$

(Date: 10/11/2015)

9- Gilaninia, Shshram and Others (December 2011): Comparative Study of Lean and Agile Supply Chain Management along with the Optimal Model Presentation of Agile Supply Chain Management", In (Arabian Journal of Business and Management Rview), Vol.1, No.4.

10- Hamel, Gary (2012): "Oranizational Agility", Management Performance International Inc., at the website: (http://managementperformance.com/organizational-agility/) (Date: 15/11/2015)

11- Harraf, Abe and Others (March/April 2015): "Organizational Agility", In (The Journal of Applied Business Research), Vol. 31, No. 2.

12- Hosseini, Seyyed Abdolrasoul and Others ( 2013): "The Role of Servant Leadership in Organizational Agility", $\underline{\text { In }}$ (European Online Journal of Natural and Social Sciences), Vol.2, No.3. 
13-Mehrabi, Soheila and Siyadat, Sayyed Ali and Allameh, Sayeed Mohsen (May 2013): "Examining the Degree of Organizational Agility from Employees' Perspective", $\underline{\text { In }}$ (International Journal of Academic Research in Business Social Science), Vol.3, No.5.

14-Su,Guangya: "Exploring Requirements of Agility for Knowledge Management", at the website: (http://subs.emis.de/LNI/proceedings/proceeding182/371.pdf) (Date: 10/11/2015)

15- USAID (October 2010): "Human and Institutional Capacity Development Handbook", Office of Education, Burea for Economic Growth Agriculture and Trade.

16- Wendler, Roy (2013): "The Structure of Agility from Different Perspectives", In (Federated Conference on Computer Science and Information Systems).

17- Wendler, Roy and Dresden, Tu (2014):"Development of the Organizational Agility -Maturity Model", In (Federated Conference on Computer Science and Information Systems).

18-Yaghoubi, Nour Mohammad and Sarabandi, Parisa and Banihashemi, Seyyed Ali (2011): "Strategies for improving Agility in Organizations", In (European Journal of Humanities and Social Sciences), Vol.7, No.1.

19- Yeganegi, Kamran and Saber Zahiri, Mohammad (3-6 July 2012): "The Effect of IT on Organizational Agility", In (The International Conference on Industrial Engineering and Operations Management), Istanbul, Turkey. 